\title{
Essência papeleira de reflorestamento II - O Pinus caribeae (variedade hondurensis) introduzido na Amazônia (*)
}

\author{
Antonio de Azevedo Correa $\left(^{* *}\right)$ \\ Cláudio Nazareno Reis Luz (**)
}

\begin{abstract}
Resumo
Uma amostra de Pinus caribeae var. honduren. sis introduzida na Amazônia foi estudada sob o ponto de vista de celulose e papel. Inicialmente mostra-se a distribuição geográfica das florestas de Pinus tropicais. Em seguida evidencia-se a utilização desta essência, como matéria-prima para a indústria de pasta e papel em alguns países em desenvolvimento, assim como as principais pesquisas visancio a sua utilização. Informações da área de coleta, características dos plantios, classificação e micrometria das fibras, qualidades das pastas cruas, alvejadas e clarificadas dos diversos procedimentos são fornecidos. Concluindo-se que a despeito do material papeleiro deste resinoso não sor comparável aos Pinus do hemisfério norte, as qualidades de suas pastas o credenciam como uma essência papeleira de reflorestamento.
\end{abstract}

\section{FITOGEOGRAFIA DOS PINUS TROPICAIS}

As florestas de Pinus ccupam uma superficie considerável no hemisfério norte. O gênero Pinus, que compreende cerca de 120 espécies, possuem exigências ecológicas muito vizinhas, principalmente no que diz respeito à pluviosidade e temperatura, correspondendo essencialmente a climas temperados e subtropicais (Tissot 1968).

As espécies de Pinus, que se encontram em zonas intertropicais, raramente estão situadas a baixa altitudes e se localizam geralmente em altitudes, cuja temperatura é inferior a $23^{\circ} \mathrm{C}$ (lbid.).

Na Ásia, os Pinus mais importantes são os Pinus merkussi e khasya, que são encontrados nessas regiōes em florestas caracterizadas como "Montanhas de Coníferas Tropicais", existindo na Indonésia, Burna, Tailândia, Vietnã, Laos, Cambodja, Sumatra, ocupando áreas de baixa umidade, cuja altitude varia de 100 a $900 \mathrm{~m}$, chegando a constituir formação de "Clímax", não obstante a disputa por espaço (Sewendono 1956). Vale realçar que o Pinus merkussi pode ser considerado o mais tropical dos Pinus, uma vez que, na Sumatra, ele se aproxima do Equador cerca de $2^{\circ} \mathrm{N}$ (Tissot, 1968).

A ecologia do Pinus khasya (Syn-P. insularis da Filipinas) é bastante semelhante ao do Pinus merkussi, mas esta espécie não chega a ultrapassar para o sul a latitude de $12^{\circ} \mathrm{N}$. Nessa região ele se situa abaixo $750 \mathrm{~m}$ de altitude (Ibid.).

$\mathrm{Na}$ América Central, uma área muito ext€nsa, que se propaga desde a Guatemala até ao México, é ocupada por floresta do tipo úmida, onde se verifıca a presença dos Pinus tropicais. Nas Antilhas, a espécie mais freqüente é a dos $P$. ocidentalis e no continente são os $P$. pseudostrobus, $P$. tenuifolia e Pinus patula e nas margens desta região encontram-se simultaneamente os $P$. oocarpa, $P$. montezumae, associados geralmente com várias espécies de carvalho (Holdrige, 1956).

Os Pinus mexicanos, cujo número de espécies ultrapassam de quarenta, estão localizados principalmente entre $30^{\circ}$ e $15^{\circ}$ latitude norte, possuem ecologia muito variada; entretanto, somente o P. strobus var. chiapensis desce até a altitude de $600 \mathrm{~m}$, na latitude de $16^{\circ} \mathrm{N}$. Os outros que se situam entre $1.500 \mathrm{~m}$ a $3.000 \mathrm{~m}$, ocupam diversos tipos climáticos: subtropicais, temperado quente, temperado frio (Tissot, 1968).

O gênero Pinus é representado desde o norte da Nicarágua, cerca de $12^{\circ} \mathrm{N}$. por três espécies: $P$. caribeae var. hondurensis ientre

\footnotetext{
(") - Trabalho apresentado na VIII Convenção Anual da Associação Brasileira de Celulose e Papel, realizada na cidade de São Paulo, no período de 17 a 21 de novembro de 1975.

[*] - Instituto Nacional de Pesquisas da Amazônia, Manaus.
} 
0 e $600 \mathrm{~m}$ de altitude), $P$. oncarpa (entre $600 \mathrm{e}$ $1.700 \mathrm{~m}$ j e P. pseudostrobus (entre $1.200 \mathrm{e}$ $1.700 \mathrm{~m}$ ) (Ibid.).

Estas duas últimas espécies dirigem-se para o norte até o sul do México, porém o $P$. caribeae var. hondurensis atinge somente a Guatemala e a Honduras Britânica, sempre a baixas altitudes (Ibid.).

O P. caribeae var. caribeae do oeste de Cuba é do tipo subtropical e o $P$. caribeae var. bahamensis é do tipo menos tropical. Nas ilhas Caraibas (Cuba, Haiti, República Dominicana) encontram-se outros Pinus subtropicais: $P$. ocidentalis, $P$. tropicalis e P. cubensis (Ibid.)

Na África Tropical, não existe Pinus, uma vez que, no continente africano o gênero penetra em pequenas proporções para o sul até a latitude de $28^{\circ} \mathrm{N}$. com a espécie $P$. canariensis das ilhas Canárias. O povoanıento de Pinus da África Setentrional (sobretudo P. halapensis), corresponde a clima mediterrâneo (lbid.).

\section{FOVOAMENTO PURO DE PINUS TROPICAIS}

Os Pinus tropicais foram introduzidos com sucesso em quase todas as regiões subtropicais e tropicais (lbid.).

Na África, ao sul do Saara e em Madagascar foram adaptadas diversas espécies de Pinus. As mais antigas foram:

- Pinus patula (originário do México), que se encontra em abundância na República SulAfricana, Kenya, Swaziland e nos altos planaltos de Madagascar;

- Pinus Khasya, introduzidos na Rodésia, Ouganda e Madagascar;

- Finus ellioti (sul do oeste dos Estados Unidos) e $P$. pinastre adaptados no Natal e Transval;

- P. caribeae adaptado e cobrindo grandes superficies no Natal.

Os bosques de Pinus exóticos cobrem uma superfície de 220.000 ha na Africa do Sul e 22.000 ha em Madagascar (lbid.).

Os 220.000 ha da República Sul Africana, compostos por $40 \%$ de Pinus patula e Pinus ellioti e $60 \%$ de Pinus pinastre, taeda, radiata, longitólia, canariensis, caribeae. É interes- sante observar que a África do Sul possui climas bastante variáveis, estando os climas temperado e subtropical largamente difundidos, existindo variaçóes climáticas com chuvas de verão à chuvas regulares de estação de inverno (lbid.).

Os 22.000 ha dos povoamentos de Madagascar sáo compostos por P. patula (lbid.).

No Malawi os povoamentos de Pinus patula e Pinus ellioti, cobrem uma superfície considerável no planalto de Vipya (altitude $2.134 \mathrm{~m}$ ), apresentando uma taxa de crescimento superior a $17,5 \mathrm{~m}^{3}$ de madeira por hectare (volume pleno) (Palmer et. al., 1974).

$\mathrm{Na}$ América Latina, a criação de bosques artificiais tem sido intensificada, atingindo o ritmo de plantações em 1970, uma ordem de 200.000 Ha/Ano (FAO-1970). Provavelmente, grandes parcelas dêstes reflorestamentos serão cobertos com Pinus tropicais.

Entre os países limítrofes com a área amazônica, destaca-se a iniciativa do Suriname, com uma área plantada de cerca de 8.000 ha (FAO, 1974).

No Brasil, o reflorestamento com Pinus tropicais já cobre uma superfície superior a 500.000 ha, calculando o I.B.D.F.(') que em 1983 esta área ultrapassará a 900.000 ha.

No Quadro I apresentamos a distribuição desses plantios por Estados.

\section{QUADRO - I}

Áreas reflorestadas e a serem reflorestadas com Pinus tropicais no Brasil em hectares

\begin{tabular}{l|c|c}
\hline \multicolumn{1}{c|}{$\begin{array}{c}\text { Estados da } \\
\text { Federação }\end{array}$} & $\begin{array}{c}\text { Areas reflo- } \\
\text { restadas - ha } \\
\text { (1966-1973) }\end{array}$ & $\begin{array}{c}\text { Projeções de } \\
\text { refloresta- } \\
\text { mento-ha } \\
\text { (1974-1983) }\end{array}$ \\
\hline Rio Grande do Sul & 32.926 & 31.875 \\
Santa Catarina & 121.784 & 134.619 \\
Paraná & 194.867 & 166.260 \\
São Paulo & 143.091 & 33.004 \\
Minas Gerais & 36.533 & 33.186 \\
Espírito Santo & - & 18.093 \\
Pará & 30.000 & - \\
Brasil & 559.201 & 417.037 \\
\hline Brasil (1966-1983) & 976.238 & \\
\hline
\end{tabular}

FONTE: Instituto Brosileiro de Desenvolvimerito Florestai.

(1) - Instituto Brasileiro de Desenvolvimento Florestal. 
Para o Pinus caribeae var. hondurensis, com exceção do estado do Pará, cuja área reflorestada é da ordem de 30.000 ha, não se conhece com exatidão a extensão dessas plantações, nos outros estados da Federação, uma vez que nas estatísticas do I.B.D.F., os plantios realizados $\mathrm{e}$ as projeções dos futuros reflorestamentos estão agrupados somente nos gêneros, não discriminando as espécies. Entretanto, as exigências ecológicas desta espécie $\left({ }^{2}\right)$ torna-se limitativa para a região sul, o que nos leva a supor que talvez uma superfície representativa dos plantios presente e futuro dos estados de Minas Gerais, Espírito Santo e norte de São Paulo sejam cobertos por essa essência.

\section{OS PINUS TROPICAIS COMO MATÉRIA-PRIMA} PARA A INDÚSTRIA DE CELULOSE E PAPEL

Us Pinus tropicais constituem uma matéria-prima clássica para a obtenção de pasta a papel em vários países em desenvolvimento. Os exemplos mais tradicionais são os da indủstria "Usutu Pulp Company Ltd" em Bunya Swaziland, que fabrica $100.000 \mathrm{t} / \mathrm{ano}$ de pasta "Kraft" crua, a partir de uma floresta artificial

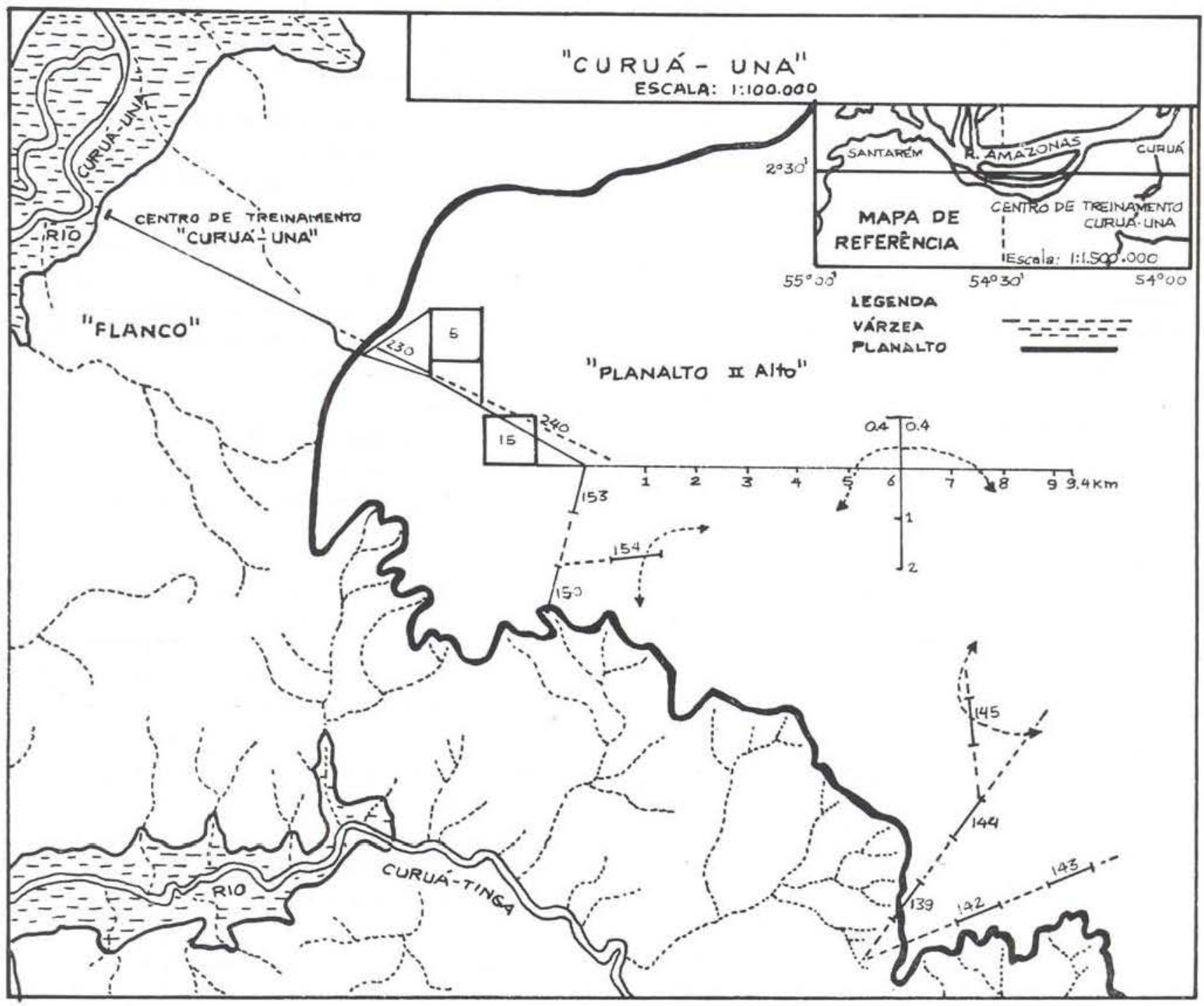

Fig. 1 - Região Flanco do Planalto de Santarém

(2) - Segundo Tissot, no Gabão e na Ponta Negra (República Popular do Congo), o Pinus caribeae e Pinus oocarpa se desenvolvem em clima quente (média anual $25^{\circ} \mathrm{C}$ ), com chuvas irregulares, variando muito de um ano a outro $(800-1.300 \mathrm{~mm})$; estação seca bem diferenciada e sclos arenosos. 
de 44.500 ha, composta de $75 \%$ de Pinus patula, $24 \%$ de Pinus elliotii, $4 \%$ de Pinus taeda e $1 \%$ de outros Pinus, inclusive caribeae, plantado com sucesso em baixas altitudes (Dubois 1966) e "Papetrie" de Madagascar, que fabrica $3.000 \mathrm{t} /$ ano de pasta mecânica, utilizando Pinus patula (Tissot, 1968).

Por outro lado, as prospecções efetuadas a nivel de laboratório, originaram uma documentação considerável, destacando-se as pesquisas levadas a efeito por: Tissot, 1968; Petroff et Alii, 1968; Paimer et Alii, 1969, 1970 , 1971, 1972, 1973, 1974 e Chong, 1973, onde os Pinus tropicais de diferentes regiões do globo foram analizados, visando a obtenção desde pasta mecànica, até celulose solúvel.

\section{AMOSTRAS DE PINUS CARIBEAE, VARIEDADE HONDURENSIS, ESTUDADAS PELA SECÇÃO DE CELULOSE E PAPEL DO INPA}

As amostras estudadas, corresponderam a duas árvores diferentes originárias da região de Flanco do Planalto de Santarém (fig. 1), relativas a um plantio experimental, realizado peıa missão F.A.O. na Amazónia, em março de 1950 , com sementes provenientes das montanhas de "Pine Ridge das Honduras Britânicas (Dubois, 1971)".

Essta área está localizada entre os rios Tapajós e Xingu. Sua posição geográfica é equatorial com $2^{\circ} 23^{\prime}$ latitude sul e $54^{\circ} 24^{\prime}$ longitude oeste. É cortada pelo rio Curuá, cujo regime enchente/vazante apresenta uma média de 4 meses. Seu clima é tropical, caracterizado por uma estação seca, com menos de $50 \mathrm{~mm}$ de precipitação, por mês, que vai de junho até outubro, ocorrendo freqüentemente em quase todos os anos um prolongamento desta estação, durante o mês de janeiro, com duração de uma a três semanas. A precipitação média anual é da ordem de $1720 \mathrm{~mm}$. A média mensal das temperaturas máxima variam de 30 a $34^{\circ} \mathrm{C}$. A média de variaçāo das temperaturas mínimas estão na ordem de 21,5 a $28,1^{\circ} \mathrm{C}$. A temperatura média anual corresponde a $27,5^{\circ} \mathrm{C}$ (lbid.).

Três tipos de floresta ocorrem nesta região: a) Flovesta de várzea (edáfica, formação extra-zonalj bordejando o rio, sendo periodicamente inundada pelas enchentes; b) Floresta para-clímax de flanco, pobre em solos arenosos, estendendo-se desde a várzea baixa até ao pé das elevações agruptas, que contornam a parte mais alta do falso planalto; c) Floresta de planalto (série clímax), sobre solos argilosos pesados (Ibid.).

A característica dos plantios e os resultados obtidos com 98 meses de idade antes e após ao debaste foram os seguintes:

a) Características do plantio:

- densidade inicial $-2,5 \mathrm{~m} \times 2,5 \mathrm{~m}(1.600$ planta/ha)

- plantio efetivado com raíz desnuda

- número inicial plantado - 200 (lbid.).

b) Resultados observados (98 meses de idade) antes do debaste:

- número de indivíduos vivos - 178 (89\% de sobrevivência).

— área basal - 31,66 $\mathrm{m}^{2} / \mathrm{ha}$

- volume total $-260,3 \mathrm{~m}^{3} / \mathrm{ha}$

- incremento anual médio do volume $31,8 \mathrm{~m}^{3} /$ ha

- maior diâmetro até $1,5 \mathrm{~m}-26 \mathrm{~cm}$

- menor diâmetro - $16 \mathrm{~cm}$

- incremento anual médio do diâmetro $1,9 \mathrm{~cm}$

- maior altura $-23 \mathrm{~m}$

- menor altura $-14 \mathrm{~m}$

- incremento anual médio da aitura $1,7 \mathrm{~m}$ (Ibid.).

c) Alguns valores observados após o debaste:

- número de árvores não suprimidas $126(948 / \mathrm{ha})$ das quais $88(724 / \mathrm{ha})$ dominante e co-dominante

- número de indivíduos não suprimidos 88 , correspondendo a $224 / \mathrm{ha}$.

- área basal 88 não suprimida $-18,4 \mathrm{~m}^{2} /$ ha

28 suprimida $-1,49$

Total - 19,89 $\mathrm{m}^{2} / \mathrm{ha}$

- volume total 88 nâo suprimida - $160,14 \mathrm{~m}^{3} / \mathrm{ha}$ 28 suprimida $-9,20 \mathrm{~m}^{3} / \mathrm{ha}$ Total - 169,34 $\mathrm{m}^{3} / \mathrm{ha}$.

- maior diâmetro até $1,5 \mathrm{~m}-26 \mathrm{~cm}$.

- menor diâmetro $-14,7 \mathrm{~cm}$.

- incremento anual médio do diâmetro $18 \mathrm{~cm}$. 


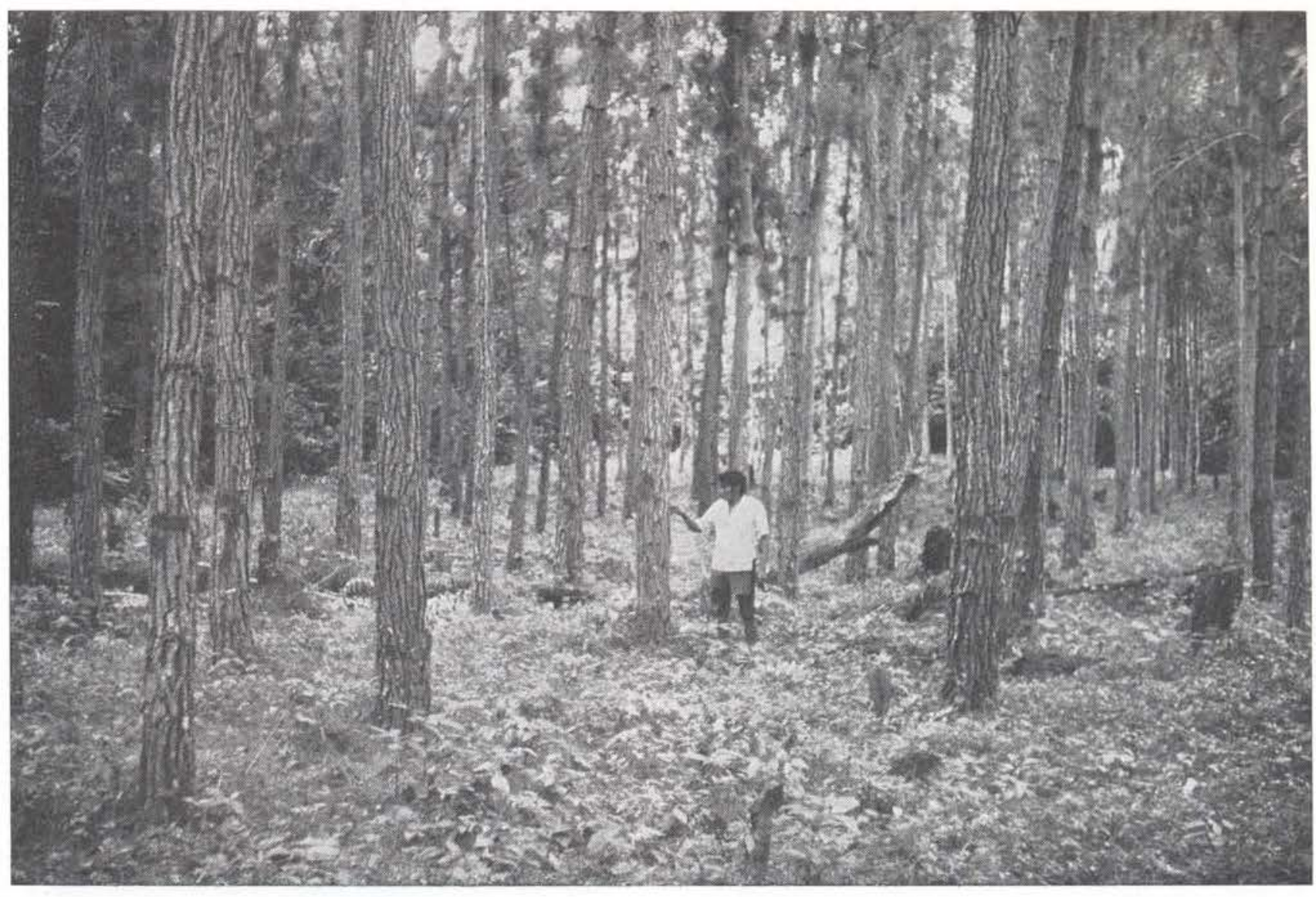

Fig. 2 - Plantio com 9 anos de idade. Foto: M. Pedroso.

- menor diâmetro das não suprimidas 17,8 (com incremento anual médio) $2,1 \mathrm{~cm}$.

- maior altura $-23 \mathrm{~m}$

- menor altura - $16 \mathrm{~m}$ (incremento anual médio $1,9 \mathrm{~m}$ ) (lbid.).

\section{CLASSIFICAÇÃO, CARACTERISTICAS MICROMÉTRICAS DAS FIBRAS E DENSIDADE DA MADEIRA}

Das pastas provenientes dos cozimentos Soda-Enxofre efetuou-se a classificação dos comprimentos das fibras segundo o procedimento TAPPI-T233-SU-64 em Classificador de Fibras "Clark", modelo M-46. Das partes retidas em cada compartimento realizou-se mensuraç̃̃es em Projetor Olympus - 4P-360.

As larguras das fibras e das cavidades foram dimensionadas em Microscópio mono. - ocular E. Leitz, com lente ocular 10X, objetiva $43 \mathrm{X}$ e fator 3,14 .
Ós resultados estão consignados na Tabela $n .^{\circ}$ I.

Como se observa, o Pinus caribeae possui 5 (cinco) dımensões de fibras bem distintas, sendo que as de maiores comprimentos corresponderam a quase $50 \%$ do total.

As larguras das fibras nos diversos compartimentos variaram de $48 \mathrm{Mu}$ a $65 \mathrm{Mu}$. notando-se que existe uma tendência das mesmas em acompanhar os decréscimos dos comprimentos, com valores intermediários aproximando-se entre si. A mesma propensão é verificada para as larguras das cavidades, cujos valores na pasta classificada variaram de 30 $\mathrm{Mu}$ a $55 \mathrm{Mu}$.

Estas observações nos levam a fazer as seguintes consideraçôes:

a) $48 \%$ das fibras das pastas classificadas do Pinus caribeae correspondem às fibras Iongas e largas; 


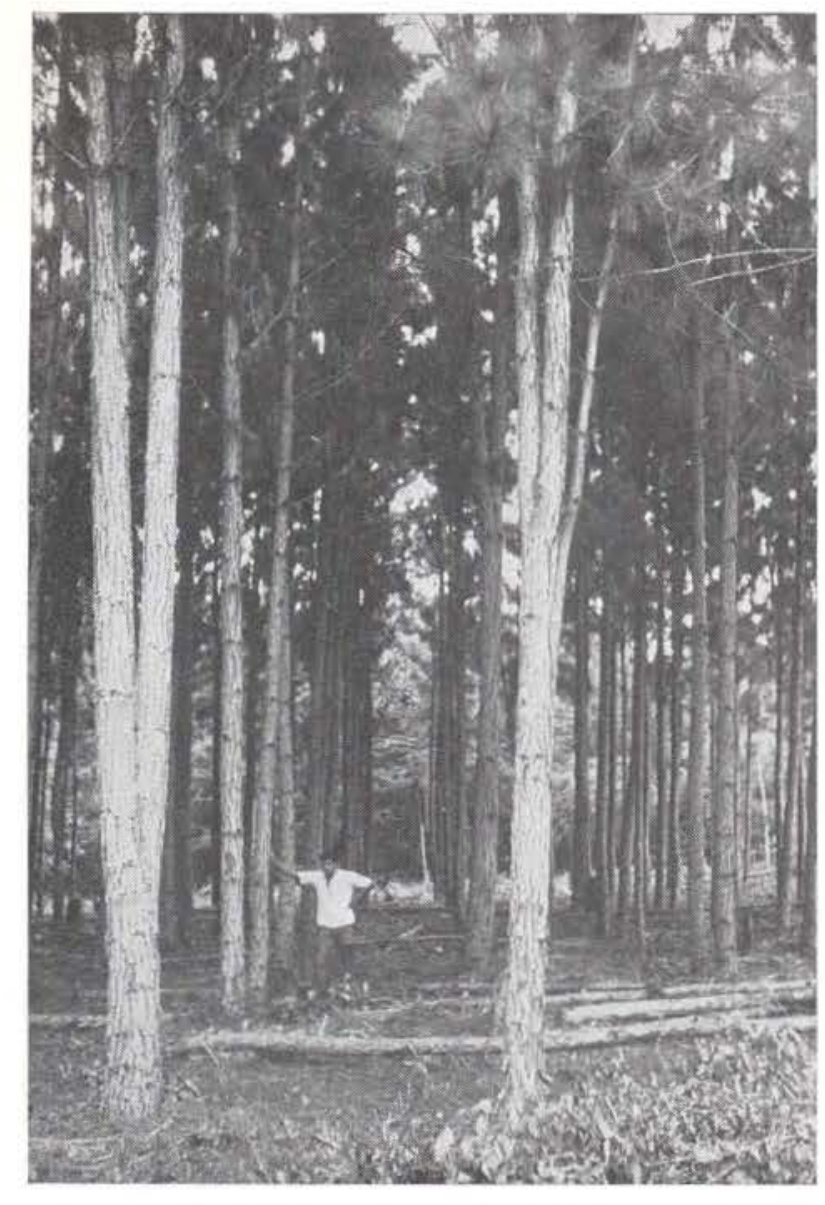

Fig. 3 - Plantio com 10 anos de idade. Foto: M. Pedroso.

b) $34 \%$ das fibras equivalem a um tamanho intermediário com larguras muito próximas;

c) $1 \%$ corresponde a um tamanho menor, com larguras inferiores às precedentes;

d) $17 \%$ são devidas as fibras mais curtas. valor do comprimento calculado e largura desconhecida.

O coeficiente de flexibilidade foi calculado para os 4 (quatro) tipos de fibras mensuradas, apresentando valores elevados e muito próxi. mos; caracterizando serem as fibras bastantes plásticas susceptiveis de fornecerem papéis de boa qualidade.

O poder filtrante variou de 68 a 23 e este declínio estả relacionado com os decréscimos observados para os comprimentos e larguras.
Considerando a importância para a avaliação da qualidade de uma pasta do peso médio dos comprimentos das fibras (Clark 1962), calculou-se este parâmetro para as fibras das pastas do Pinus caribeae através da fórmula:

$$
L=\frac{W_{1} 1_{1}+W_{2} 1_{2}+W_{3} 1_{3}+W_{4} 1_{4}+W_{5} 1_{5}}{W}
$$

Onde:

$\mathrm{L}=$ Peso médio do comprimento da fibra
$\left(1_{1}, 1_{2}, 1_{3}, 1_{4}\right)=$ Comprimento das fibras nos diversos compartimentos do classificador.

$1_{5}=$ Peso da amostra calculado por diferença. $\mathrm{W}=$ Peso inicial da amostra.

O resultado obtido foi de uma ordem de grandeza de $3,238 \mathrm{~mm}$.

No conjunte os diversos valores apresentados pelas características fibrosas das pastas do Pinus caribeae, bem como pela sua densidade, são normais e estão perfeitamente configurados dentro dos padrões conhecidos para os resinosos.

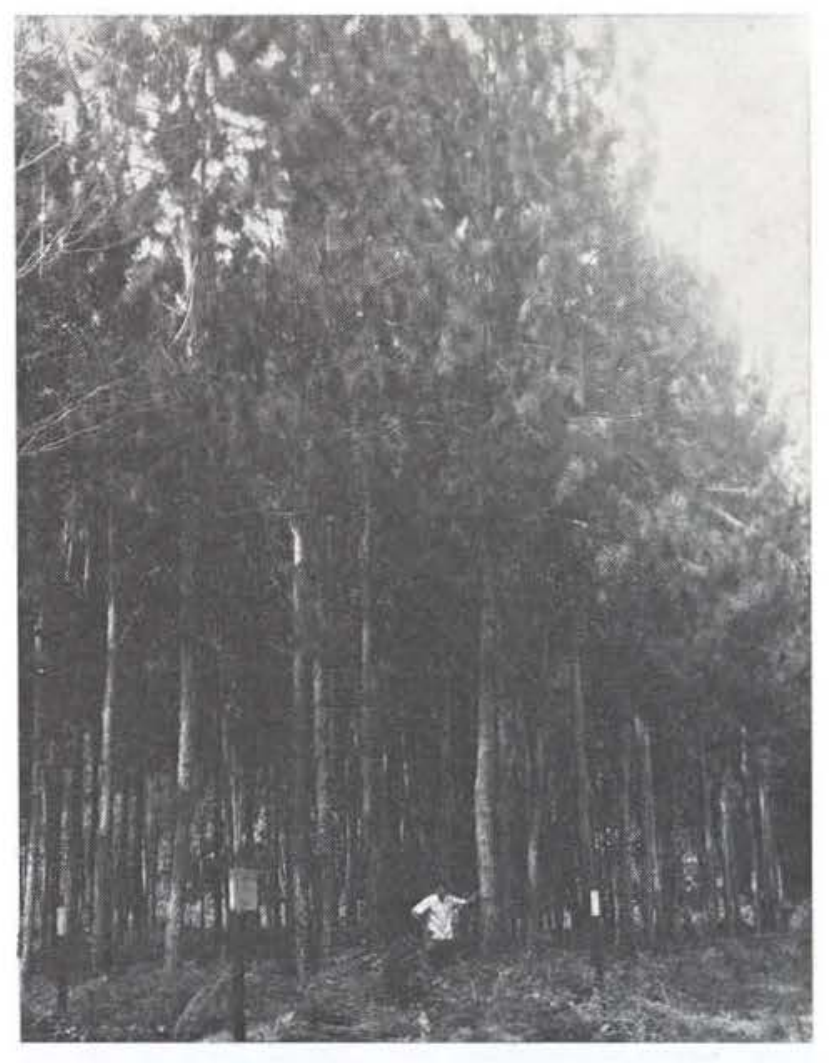

Fig. 4 - Plantio com 11 anos de idade - Planalto Foto: M. Pedroso. 
TABELA N. 1

Classificação, características micrométricas das fibras e densidade da madeira

\begin{tabular}{|c|c|c|c|c|c|}
\hline \multirow{2}{*}{ CARACTERISTICAS } & \multicolumn{5}{|c|}{ COMPARTIMENTOS } \\
\hline & N.ค 1 & N.० 2 & N. 3 & N. 4 & $\begin{array}{c}\text { Abaixo 1125 } \\
\text { (Mu) }\end{array}$ \\
\hline $\begin{array}{l}\text { Comprimento das fibras } \\
\text { (Mu) }-\mathrm{L}-\text { valores médios }\end{array}$ & 4454 & 3243 & 2084 & 1125 & 706 \\
\hline $\begin{array}{l}\text { Largura das fibras }(\mathrm{Mu}) \\
1 \text { - valores médios }\end{array}$ & 65 & 51 & 52 & 48 & \\
\hline $\begin{array}{l}\text { Larguras das cavidades } \\
(\mathrm{Mu})-\mathrm{C}-\text { valores médios }\end{array}$ & 44 & 34 & 33 & 30 & \\
\hline Coeficiente de flexibilidade $\mathrm{C} / 1$ & 68 & 67 & 63 & 62 & \\
\hline Poder feltrante $\mathrm{L} / 1$ & 68 & 63 & 40 & 23 & \\
\hline$\%$ retirada em cada compartimento & 48 & 22 & 12 & 1 & 17 \\
\hline Densidade & \multicolumn{5}{|c|}{0,32} \\
\hline
\end{tabular}

Volor calculado segundo método TAPPI - T - 232 - SU - 68

\section{COMPOSIÇÃO QUÍMICA DA MADEIRA}

As análises químicas das madeiras foram efetuadas segundo as normas do TAPPI $\left({ }^{3}\right)$ e A.B.C.P. $\left({ }^{4}\right)$.

Os resultados apresentados na Tabela $n$. $^{3}$ II mostram que não houve variação significativa entre as duas amostras, com exceção dos teores de álcool benzol e soda $1 \%$, que apresentaram para a amostra $\mathrm{n}^{\circ} 2$ taxas mais elevadas. Estas diferenças talvez estejam relacionadas com o tempo de estocagem, uma vez que as análises efetuadas sobre a amostra $n .{ }^{\circ}$ 2 foi quase que imediata a sua recepção no laboratório, enquanto as efetuadas sobre a primeira amostra foram realizadas após um maior período de estocagem.

O teor de resina caracteristica dessas essências está relacionado com a extração ao álcool benzol e pode constituir-se em um inconveniente ou em uma vantagem, na sua utilizaçäo para fabricação de pasta a papel. Nas cocções "Kraft" a resina fornece um subproduto: o "tail-oil", composto de sais alcalinos e ácidos resinosos, recuperados da superfície dos licores negros. O rendimento do "tall-oil" nos resinosos de clima temperado, variam de 25 a $80 \mathrm{~kg}$ por toneladas de pastas fabricadas. Pode-se extrair antecipadamente a resina antes de levar a madeira à fabrıcação, por sangria na própria árvore, mas esta operaçâo só é rentável quando se trata de plantio racional.

A inconveniência que a resina causa à fa. bricação de pasta, decorre do fato da mesma proporcionar o aparecimento de espumas nos sistemas de lavagem e depuração.

Entretanto, este inconveniente pode ser combatido pela utilização de agentes tensoativos, como o querosene. Por outro lado, as resinas originam depósitos de breu no circuito de fabricação.

Na fabricação de pastas mecânicas a resina é igualmente causadora de desgaste dos dentes do desfibrador e das telas metálicas da máquina de papel. Em relação aos demais parảmetros apresentados nas análises quírnicas, observa-se que eles são compativeis com resinosos tropicais já consagrados pela indústria papeleira como o Pinus patula de "Usutu".

(3) - TAPPI - Technical Association of the Pulp and Paper Industry.

(4) - A.B.C.P. - Associação Brasileira Técnica de Celulose e Papel.

Essência papeleira... 
TABELA N.॰ II

Composição química do Pinus caribeae - Var. hondurensis da região de Santarém

\begin{tabular}{|c|c|c|c|c|c|c|c|c|c|}
\hline AMOSTRAS & $\begin{array}{c}\text { Sol. em } \\
\text { água fria } \\
\%\end{array}$ & $\begin{array}{c}\text { Sol. em } \\
\text { água } \\
\text { quente - \% }\end{array}$ & $\begin{array}{l}\text { Sol. } \\
\text { Soda } \\
\% \\
\%\end{array}$ & $\begin{array}{c}\text { Sol. em } \\
\text { álcool } \\
\text { benzol - \% }\end{array}$ & $\begin{array}{l}\text { Lignino } \\
\%\end{array}$ & $\begin{array}{c}\text { Pentosanas } \\
\%\end{array}$ & $\begin{array}{c}\text { Celulose } \\
\text { bruta } \\
\%\end{array}$ & $\begin{array}{c}\text { Celulose } \\
\text { corrigida }\end{array}$ & Cinzos \\
\hline Amostra n. ${ }^{\circ} 1$ & 2,05 & 2,05 & 6,49 & 3,60 & 26,65 & 7,49 & 46,67 & 45,68 & 0,11 \\
\hline Amostra n. 2 & 2,98 & 3,43 & 4,94 & 5,89 & 27,41 & 7,05 & 5475 & 48,98 & 0,19 \\
\hline
\end{tabular}

\section{COCČÃO "KRAFT"}

Duas séries de cozimentos foram efetuados pelo procedimento Soda/Enxofre (variante do processo "Kraft"J a $155^{\circ} \mathrm{C}$ e a $170^{\circ} \mathrm{C}$ em cozinhador rotativo de 10 litros, aquecimento elétrico e 1 r.p.m.

As condições retidas para a efetivação dos cozimentos foram as seguintes:

\begin{tabular}{l|r|r}
\hline Condições & $\mathbf{1 7 0} \mathbf{C}$ & $\mathbf{1 5 5 ^ { \circ } \mathbf { C }}$ \\
\hline NaOH/Mad. Sêca & $22 \% 24 \% 26 \%$ & $22 \% 24 \% 26 \%$ \\
$\begin{array}{l}\text { Enxôfre/Mad. Sêca } \\
\text { Diluição }\end{array}$ & $3,2 \% 2,4 \% 2,6 \%$ & $2,2 \% 2,4 \% 2,6 \%$ \\
$\begin{array}{l}\text { Tempo na Temp. } \\
\text { de Patamar }\end{array}$ & 120 Min. & $3,3: 1$ \\
$\begin{array}{l}\text { Tempo na Temp. } \\
\text { de Patamar }\end{array}$ & 90 Min. & 180 Min. \\
\hline
\end{tabular}

As pastas obtidas dos cozimentos foram desintegrados logo após a degasagem em "Pulper" de laboratório "Allibe" (tendo-se antes retirado uma amostra do licor negro para a determinação do $\mathrm{NaOH}$ residual), lavadas depuradas em Depurador Brecht Holl, (peneira 0,6 $\mathrm{mm}$ ) e desaguada até a consistência de $30 \%$ em centrífuga S.A. 30 AW 2, Rousselet a 1.500 rpm, determinando-se em seguida os rendimentos brutos e depurados, rejeitos sobre a madeirá seca e número de permanganato.

Os resuitados obtidos apresentamos na $\mathrm{Ta}$ bela n.․II.

E possivel obter pastas bem deslignificadas a partir de um nível de $24 \%$ de $\mathrm{NaOH} / \mathrm{Ma}$ deira Seca a $170^{\circ} \mathrm{C}$. Os cozimentos a $155^{\circ} \mathrm{C}$ com 3 horas de patamar nos três níveis de
Soda, corresponderam as pastas duras, com índice de deslignificação baixo, o que nos leva a crer da necessidade de prolongar o tempo de cocção, que representaria um inconveniente em termos de realizaçäo industrial. Para os cozimentos a $170^{\circ} \mathrm{C}$ os teores de $\mathrm{NaOH}$ (residual), foram ascendentes, na medida em que se elevou as percentagens de $\mathrm{NaOH} /$ Madeira Seca, o que é normal, uma vez que os indices de desỉignificação $\left(\mathrm{N} .{ }^{\circ} \mathrm{KMnO}_{4}\right)$ evoluíram no mesmo sentido. Este comportamento foi também veriticado para as cocções a $155^{\circ} \mathrm{C}$, com uma diferença caracterizada pela difícil dissoluçăo dos componentes da madeira que acarretou talvez uma reprecipitação da lignina, distinguido pelos baixos níveis de deslignificação apresentados.

Os rendimentos foram satisfatórios (acima de $48 \%$ ), apresentando, no entanto, as cocçōes a $170^{\circ} \mathrm{C}$ melhores resultados.

As alvuras das pastas foram equivalentes para os dois parâmetros retidos.

\section{ALVEJAMENTO DAS PASTAS CRUAS DOS COZIMENTOS SODA/ENXŌFRE}

As pastas obtidas dos cozimentos Soda! Enxotre foram alvejadas pelos processos C.E. H.H. e C.E.D.P.D. Os resultados estão contidos nas tabelas $\mathrm{n}^{\bullet} \mathrm{s}$. IV e V.

Como se verifica, o maior consumo de reagentes nos dois processos correspondeu às pastas que apresentaram índice de deslignificação mais baixo, isto é, cujos n? s. de $\mathrm{KMnO}_{4}$ foram superiores a 19 . Por outro lado, as pastas oriundas das cocçöes a $170^{\circ} \mathrm{C}$, ofereceram uma menor demanda de reativos do que as processadas a $155^{\circ} \mathrm{C}$ com 3 (três) horas de patamar. 


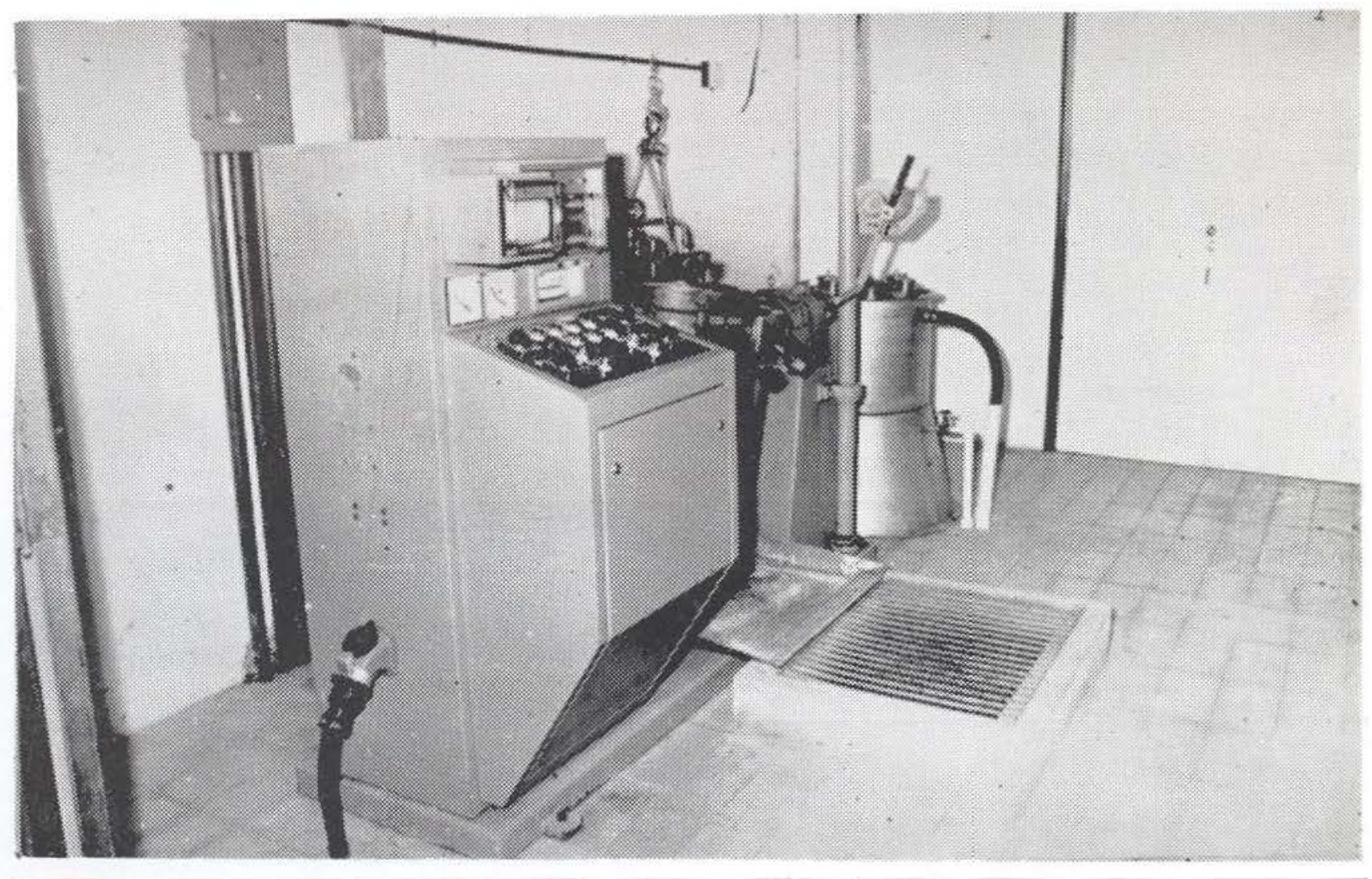

Fig. 5 - Cozinhador "Auximeca" - Capacidade 50 litros Foto: J. Romulo

E nítida a superioridade do processo C.E. D.P.D. em termos de obtenção de melhor alvura, do que o procedimento C.E.H.H.

As estabilidades das alvuras variaram em função da maior ou menor dureza das pastas.
Assim é que as pastas, nos dois processos, que exigiram maior consumo de reagentes foram as que apresentaram menor "Photovolt", mas se mostraram mais estáveis do que foram aivejadas com maior facilidade e originaram melhores alvuras.

TABELA N.० III

Resultados dos cozimentos soča/enxôfre do Pinus caribeae var. hondurensis da região de Santarém

\begin{tabular}{|c|c|c|c|c|c|c|c|c|}
\hline \multirow{2}{*}{$\begin{array}{l}\text { Número do } \\
\text { Cozimento }\end{array}$} & \multirow{2}{*}{ Patamar } & \multirow{2}{*}{$\begin{array}{c}\mathrm{NaOH} \\
\%\end{array}$} & \multirow{2}{*}{$\begin{array}{l}\mathbf{S} \\
\%\end{array}$} & \multicolumn{2}{|c|}{ Rendimento } & \multirow{2}{*}{$\begin{array}{c}\mathrm{NaOH} \\
\mathrm{g} / 1\end{array}$} & \multirow{2}{*}{ Photovolt } & \multirow{2}{*}{$\begin{array}{c}\text { Indice de } \\
\mathrm{KMnO}_{4}\end{array}$} \\
\hline & & & & $\begin{array}{c}\text { Bruto } \\
\%\end{array}$ & $\begin{array}{c}\text { Depurado } \\
\%\end{array}$ & & & \\
\hline 190 & & 23 & 2,2 & 54,44 & 54,06 & 3,2 & 25 & 30,30 \\
\hline 193 & $1 \mathrm{~h} 30^{\prime}-170^{\circ} \mathrm{C}$ & 24 & 2,4 & 54,66 & 49,12 & 5,4 & 25 & 18,00 \\
\hline 191 & & 26 & 2,6 & 54,71 & 54,54 & 10,9 & 25 & 16,83 \\
\hline 194 & & 26 & 2,6 & 49,13 & 54,62 & 8,1 & 25 & 35,68 \\
\hline 195 & $3 \mathrm{~h}-155^{\circ} \mathrm{C}$ & 24 & 2,4 & 51,67 & 51,65 & 7,0 & 25 & 41,39 \\
\hline 196 & & 22 & 2,2 & 54,88 . & 54,59 & 4,9 & 25 & 44,29 \\
\hline
\end{tabular}

Essência papeleira. . 
No conjunto, as pastas alvejadas (especialmente as oriundas das cocções a $170^{\circ} \mathrm{C}$ e processadas pelo procedimento C.E.D.P.D.) são semelhantes às melhores celuloses de resinosas, que atualmente são comercializadas no mercado internacional.
CARACTERISTICAS DAS PASTAS CRUAS E ALVEJADAS DOS PROCEDIMENTOS TIPO "KRAFT"

As pastas cruas provenientes dos cozimentos Soda/Enxofre foram refinadas em equipamentos "Jokro", "Bauer" e "Holandesa", até um grau de engorda de $45^{\circ} \mathrm{SR}$.

TABELA N. IV

Resultados dos branqueamentos (C1 - NaOH - $\mathrm{C1ONa}-\mathrm{C} 10 \mathrm{Na})$ das pastas cruas dos cozimentos soda/en. xôfre do Pinus caribeae var. hondurensis.

\begin{tabular}{|c|c|c|c|c|c|c|c|c|c|}
\hline \multirow{2}{*}{$\begin{array}{l}\text { N.० de } \\
\text { cozimento }\end{array}$} & \multirow{2}{*}{$\begin{array}{l}\text { Cloração } \\
\text { Cloro } \\
\text { consumi- } \\
\text { do } \%\end{array}$} & \multicolumn{2}{|c|}{ Sodação } & \multicolumn{2}{|c|}{ 1. Fase-C1ONa } & \multicolumn{2}{|c|}{ 2.a Fase-C1ONa } & \multirow{2}{*}{$\begin{array}{c}\text { Photovolt } \\
\text { Alvura das } \\
\text { pastas }\end{array}$} & \multirow{2}{*}{$\begin{array}{l}\text { Estabilida- } \\
\text { de da } \\
\text { alvura }\end{array}$} \\
\hline & & $\begin{array}{c}\mathrm{NaOH} \\
\text { Int. } \\
\%\end{array}$ & $\begin{array}{c}\text { NaOH } \\
\text { Cons. } \\
\%\end{array}$ & $\begin{array}{l}\text { Cloro } \\
\text { Int. } \\
\%\end{array}$ & $\begin{array}{c}\text { Cloro } \\
\text { Cons. } \\
\%\end{array}$ & $\begin{array}{c}\text { Cloro } \\
\text { Int. } \\
\%\end{array}$ & $\begin{array}{c}\text { Cloro } \\
\text { Cons. } \\
\%\end{array}$ & & \\
\hline 190 & 4,8 & 4,0 & 3,4 & 4,0 & 3,8 & 0,5 & 0,4 & 87 & 86 \\
\hline 193 & 3,0 & 4,0 & 1,6 & 4,0 & 3,7 & 0,5 & 0,3 & 87 & 84 \\
\hline 191 & 2,4 & 4,0 & 1,5 & 4,0 & 3,5 & 0,5 & 0,3 & 90 & 86 \\
\hline 194 & 3,8 & 4,0 & 2,6 & 4,0 & 3,6 & 0,5 & 0,3 & 90 & 84 \\
\hline 195 & 4,4 & 4,0 & 2,8 & 4,0 & 3,7 & 0,5 & 0,4 & 88 & 84 \\
\hline 196 & 5,0 & 4,0 & 3,5 & 4,0 & 3,8 & 1,5 & 0,9 & 87 & 83 \\
\hline
\end{tabular}

TABELA N.॰ V

Resultzdos dos alvejamentos C.E.D.P.D. [C1- $\left.\left(\mathrm{NaOH}-\mathrm{H}_{2} \mathrm{O}_{2}\right) \cdot \mathrm{ClO}_{2} \cdot \mathrm{H}_{2} \mathrm{O}_{2} \cdot \mathrm{C}_{1} \mathrm{O}_{2}\right]$ das pastas cruas dos cozimentos soda/enxôfre do Pinus caribeae - Var. hondurensis.

\begin{tabular}{|c|c|c|c|c|c|c|c|c|c|c|c|c|c|}
\hline \multirow{2}{*}{$\begin{array}{l}\text { N.॰ do } \\
\text { cozi- } \\
\text { mento }\end{array}$} & \multirow{2}{*}{$\begin{array}{c}\text { Cloração } \\
\text { Cloro } \\
\text { Cons. } \\
\%\end{array}$} & \multicolumn{4}{|c|}{ Sodação Oxídante } & \multicolumn{2}{|c|}{ 3. Fase- $\mathrm{ClO}_{2}$} & \multicolumn{2}{|c|}{ 4. Fase $-\mathrm{H}_{2} \mathrm{O}_{2}$} & \multicolumn{2}{|c|}{ 5. Fase- $\mathrm{ClO}_{2}$} & \multirow{2}{*}{$\begin{array}{c}\begin{array}{c}\text { Photo- } \\
\text { volt }\end{array} \\
\begin{array}{c}\text { Alvura } \\
\text { das } \\
\text { pastas }\end{array}\end{array}$} & \multirow{2}{*}{$\begin{array}{l}\text { Estabili- } \\
\text { dade das } \\
\text { alvuras }\end{array}$} \\
\hline & & $\begin{array}{c}-\mathrm{NaOh} \\
\text { Int. } \\
\%\end{array}$ & $\begin{array}{c}\mathrm{NaOh} \\
\text { Cons. } \\
\%\end{array}$ & $\begin{array}{c}\mathrm{H}_{2} \mathrm{O}_{2} \\
\text { Int. } \\
\%\end{array}$ & $\begin{array}{c}\mathrm{H}_{2} \mathrm{O}_{2} \\
\text { Cons. } \\
\%\end{array}$ & $\begin{array}{c}\text { Cloro } \\
\text { Int. } \\
\%\end{array}$ & $\begin{array}{c}\text { Cloro } \\
\text { Cons. } \\
\%\end{array}$ & $\begin{array}{c}\mathrm{H}_{2} \mathrm{O}_{2} \\
\text { Int. } \\
\%\end{array}$ & $\begin{array}{c}\mathrm{H}_{2} \mathrm{O}_{2} \\
\text { Cons. } \\
\%\end{array}$ & $\begin{array}{c}\text { Cloro } \\
\text { Int. } \\
\%\end{array}$ & $\begin{array}{c}\text { Cloro } \\
\text { Cons. } \\
\%\end{array}$ & & \\
\hline 190 & 4,8 & 4,0 & 2,8 & 1,0 & 1,0 & 2,6 & 2,6 & 1,0 & 0,9 & 1,3 & 1,2 & 89 & 88 \\
\hline 193 & 3,0 & 4,0 & 2,4 & 1,0 & 1,0 & 2,6 & 2,6 & 1,0 & 0,9 & 1,3 & 1,2 & 92 & 88 \\
\hline 191 & 2,4 & 4,0 & 2,1 & 1,0 & 1,0 & 2,6 & 2,5 & 0,5 & 0,4 & 1,3 & 11 & 93 & 89 \\
\hline 194 & 3,8 & 4,0 & 2,7 & 1,0 & 1,0 & 2,6 & 2,6 & 0,5 & 0,4 & 1,3 & 0,9 & 92 & 88 \\
\hline 195 & 4,4 & 4,0 & 4,0 & 1,0 & 1,0 & 2,6 & 2,6 & 1,0 & 0,8 & 1,3 & 0,9 & 92 & 88 \\
\hline 196 & 5,0 & 4,0 & 4,0 & 1,0 & 1,0 & 2,6 & 2,6 & 1,0 & 0,9 & 1,3 & 1,2 & 91 & 90 \\
\hline
\end{tabular}




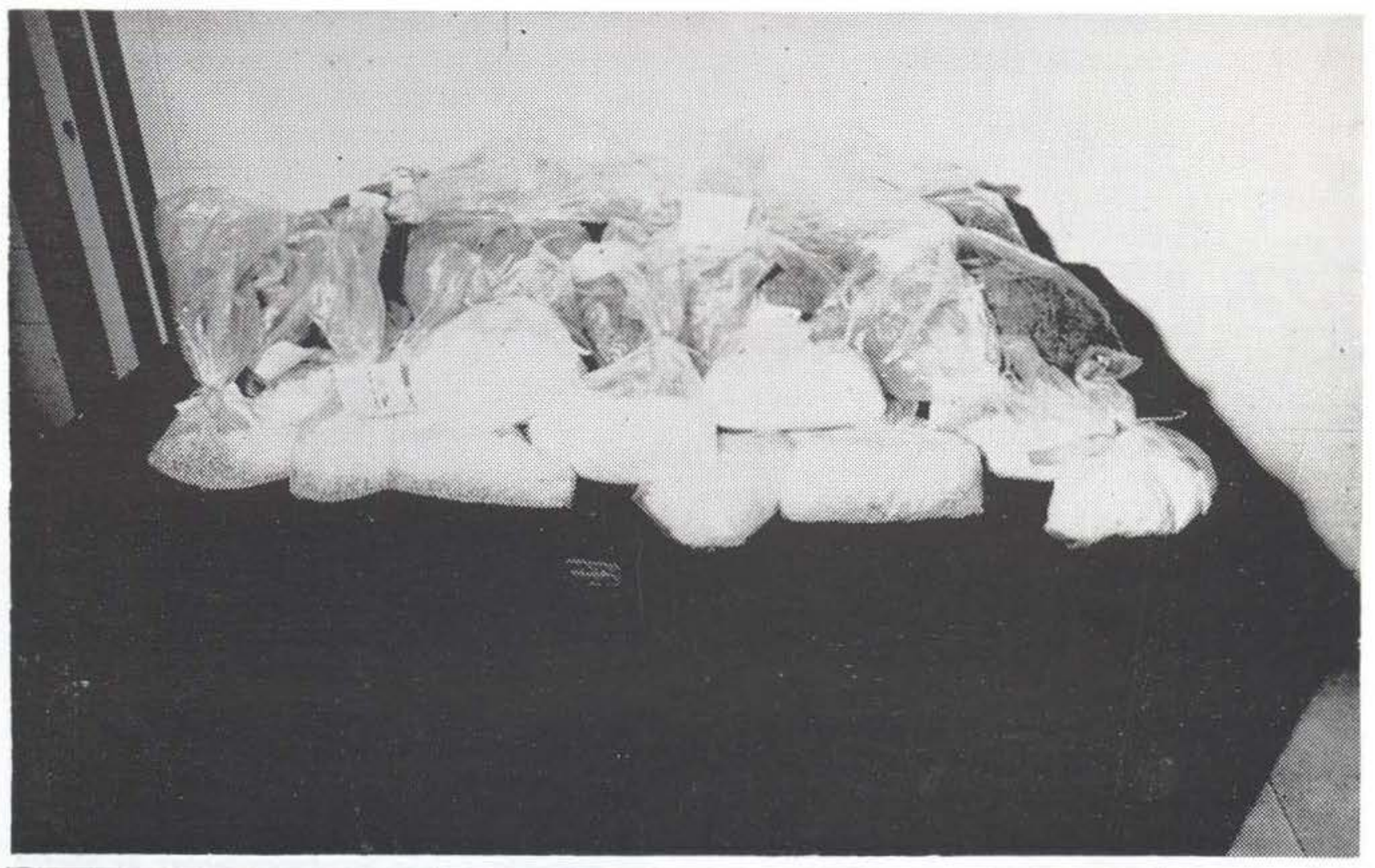

Fig. 6 - Estocagem de pastas cruas e alvejadas. Foto: J. Romulo

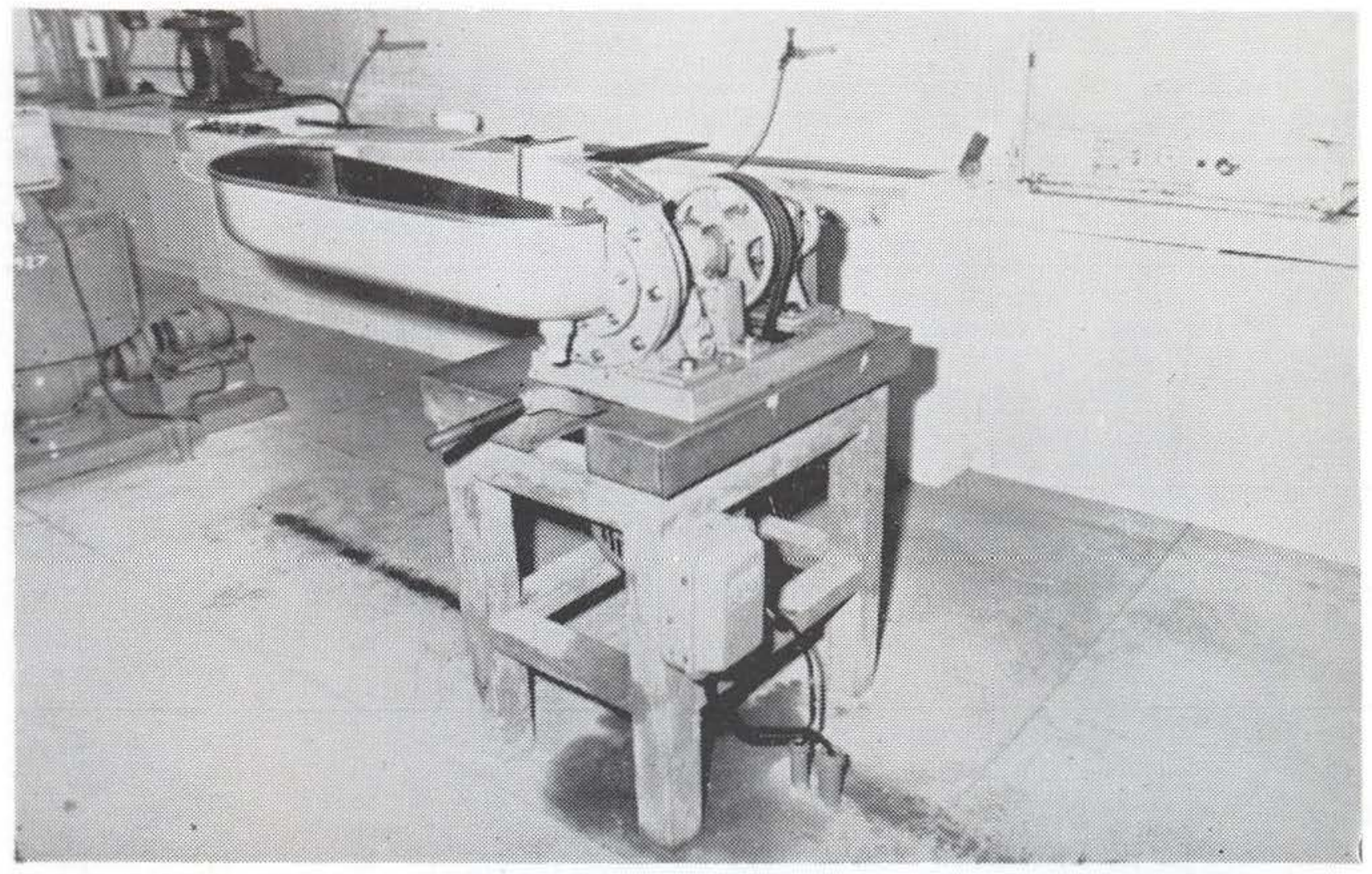

Fig. 7 - Moinho Holandesa. Foto: J. Romulo 
As refinagens das polpas não alvejadas nos três equipamentos, assim foram conduzidas:

"Jokro" - 16g de pasta seca, levada a uma consistência de $6 \%$, com 5 pontos de refino, dos quais o primeiro o ponto zero (pasta bruta), cobrindo uma escala de ${ }^{\circ} \mathrm{SR}$, que foi de $8^{\circ} \mathrm{SR}$ a $45^{\circ}-48^{\circ} \mathrm{SR}$.

"Bauer" - $16 \mathrm{~g}$ de pasta seca a uma concentração de $0,2 \%$ submetidas a uma potência de de refino de $3,72 \mathrm{KW}$, com circulação forçada. Foram realizadas passagens sucessivas (o máximo três), até atingir o grau de engrossamento desejado.

"Holandesa" - 200g de pasta seca com uma consistência de $1 \%$. A massa foi inicialmente desintegrada no próprio equipamento (operaçâo realizada com discos separados) por 30 minutos, adicionando-se em seguida a carga correspondente a $7.735 \mathrm{~g}$ e uniu-se os discos. Quatro pontos de refino foram obtidos por período de 35 minutos.
Das pastas cruas refinadas produziu-se foIhas de ensino, com gramatura aproximada de $65 \pm 5 \mathrm{~g} / \mathrm{m}^{2}$, em formador Rapid Khöten. Acondicionando-se essas amostras em sala climatizada com $65 \pm 5$ UR e $22 \pm 2^{\circ} \mathrm{C}$ por 12 horas e realizou-se os testes de resistência, obedecendo os padrões das Normas da A.B.C.P. (Associação Brasileira Técnica de Celulose e Papel), TAPPI (Technical Association of the Pulp and Paper Industry), A.F.N.O.R. (Association Française de Normalisation).

Os resultados obtidos são mostrados na Tabela n. ${ }^{\circ}$ VI.

E evidente que uma análise quantitativa comparativa dos resultados apresentados em relação ao desempenho dos equipamentos, torna-se difícil de ser realizada, em decorrência das condiçóes em que se processaram os refinos das pastas (níveis de consistência); entretanto, uma observação empírica nos leva a fazer as seguintes considerações:

- De um modo geral, os valores das características dos papéis correspondentes às pastas

TABELA N. VI

Características das pastas cruas dos cozimentos soda/enxôfre do Pinus caribeae - var. hondurensis da regiâo de Santarém, resultados interpolados a um grau de refino de $45^{\circ} \mathrm{SR}-$ Holandesa, Jokro, Bauer

\begin{tabular}{|c|c|c|c|c|c|c|c|c|c|}
\hline Equipamento & $\begin{array}{l}\text { NO DE CO- } \\
\text { ZIMENTO }\end{array}$ & $\begin{array}{c}\text { AUTO- } \\
\text { RUPTURA } \\
\mathbf{m}\end{array}$ & $\begin{array}{l}\text { RASGO } \mathrm{g} \\
\text { Por } \\
100 \mathrm{~g} / \mathrm{m}^{2}\end{array}$ & $\begin{array}{c}\text { ESTOURO } \\
\mathrm{Kg} / \mathrm{cm}^{2} \\
100 \mathrm{~g} / \mathrm{m}^{2}\end{array}$ & $\begin{array}{c}\text { DOBRAS } \\
\text { DUPLAS } \\
\text { N. } 0\end{array}$ & $\begin{array}{c}\text { POROSI- } \\
\text { DADE } \\
\text { Seg/100 ce }\end{array}$ & $\begin{array}{l}\text { LISURA } \\
\text { Seg/50 ce }\end{array}$ & $\begin{array}{c}\text { MACIEZ } \\
\operatorname{Seg} / 100 \mathrm{cc}\end{array}$ & $\begin{array}{l}\text { ALONGA- } \\
\text { MENTO } \\
\%\end{array}$ \\
\hline \multirow{6}{*}{ Holanđesa } & 190 & 2.573 & 47 & 0.0 & 3,0 & 25,0 & 27 & 30 & 1,0 \\
\hline & 193 & 3.366 & 52 & 0,0 & 2,0 & 9,0 & 24 & 39 & 1,0 \\
\hline & 191 & 2.860 & 54 & 0,0 & 3,0 & 29,0 & 29 & 34 & 1,0 \\
\hline & 194 & 1.961 & 48 & 0,0 & 2,0 & 7,0 & 14 & 41 & 1,0 \\
\hline & 195 & 2.234 & 54 & 0,0 & 2,0 & 9,0 & 22 & 44 & 1,0 \\
\hline & 196 & 2.305 & 57 & 0,0 & 2,0 & 13,0 & 22 & 39 & 1,0 \\
\hline \multirow{6}{*}{ Jokro } & 190 & 6.443 & 111 & 3,3 & 360,0 & 25,0 & 21 & 12 & 2,0 \\
\hline & 193 & 6.000 & 134 & 3,2 & 442,0 & 15,0 & 14 & 25 & 2,0 \\
\hline & 191 & 5.824 & 108 & 2,0 & 160,0 & 23,0 & 19 & 27 & 1,5 \\
\hline & 194 & 6.511 & 126 & 4,0 & 374,0 & 43,0 & 20 & 30 & 2,0 \\
\hline & 195 & 6.327 & 122 & 3,5 & 467,0 & 30,0 & 18 & 28 & 2,0 \\
\hline & 196 & 6.140 & 140 & 3,6 & 621,0 & 54,0 & 16 & 24 & 2,0 \\
\hline \multirow{6}{*}{ Bauer } & 190 & 6.287 & 161 & 3,3 & 776,0 & 54,0 & 32 & 23 & 1,9 \\
\hline & 193 & 4.138 & 130 & 2,0 & 108,0 & 8,0 & 24 & 46 & 1,5 \\
\hline & 191 & 6.258 & 155 & 3,0 & 438,0 & 74,0 & 29 & 32 & 1,6 \\
\hline & 194 & 5.492 & 156 & 2,0 & 517,0 & 45,0 & 20 & 41 & 1,5 \\
\hline & 195 & 5.106 & 129 & 2,2 & 286,0 & 57,0 & 25 & 46 & 1,6 \\
\hline & 196 & 3.851 & 121 & 1,4 & 136,0 & 25,0 & 19 & 36 & 1,3 \\
\hline
\end{tabular}


refinadas no "Jokro", e "Bauer" são comparáveis as variações que apresentam não se observa a um nível muito elevado, o que não sucede para as resistências dos papéis provenientes das polpas refinadas na "Holandesa", onde êstes valores estão muito abaixo aos observados nos dois últimos refinadores. Esta anomalia pode estar associada às condições de consistência (muito baixo) em que foi processada a operação de refino nessa instrumentação.

Uma observação mais detalhada mostra que as resistências dos papéis por equipamento assim se caracterizaram:

Auto-ruptura - Jokro > Bauer > Holandesa

Rasgo - Bauer > Jokro > Holandesa

Estouro - Jokro > Bauer > Holandesa

Dobras-Duplas - Jokro $>$ Bauer $>$ Holandesa

Porosidade - Bauer > Jokro > Holandesa

Lisura - Bauer > Holandesa > Jokro

Maciez - Holandesa > Bauer > Jokro

Alongamento - Jokro > Bauer > Holandesa
Para as pastas alvejadas utilizou-se a mes. ma metodologia aplicada nas pastas cruas, com exceção de não ter sido efetivado os ensaios de refino no moinho "Holandesa", em decorrència dos resultados apresentados nos estudos das celuloses não alvejadas, neste equipamento, não foram comparativos com os efetivados nos outros dois refinadores.

Na tabela n. ${ }^{\circ}$ VII mostra-se as características das pastas alvejadas.

A mesma observação em termos de desempenho do equipamento verificado para a massa crua, foi confirmada nas pastas alvejadas uma vez que em relação às caracteristicas mais significantes (Auto-ruptura, Rasgo. Estouro e Dobras-duplas) a mesma tendência foi satisfeita.

Em termos de avaliação papeleira intrínse. ca, para os parâmetros de cczimentos retidos, nota-se que as resistências dos papéis obtidos das pastas a $155^{\circ} \mathrm{C}$ foram superiores ao verificado com o outro padrão retido.

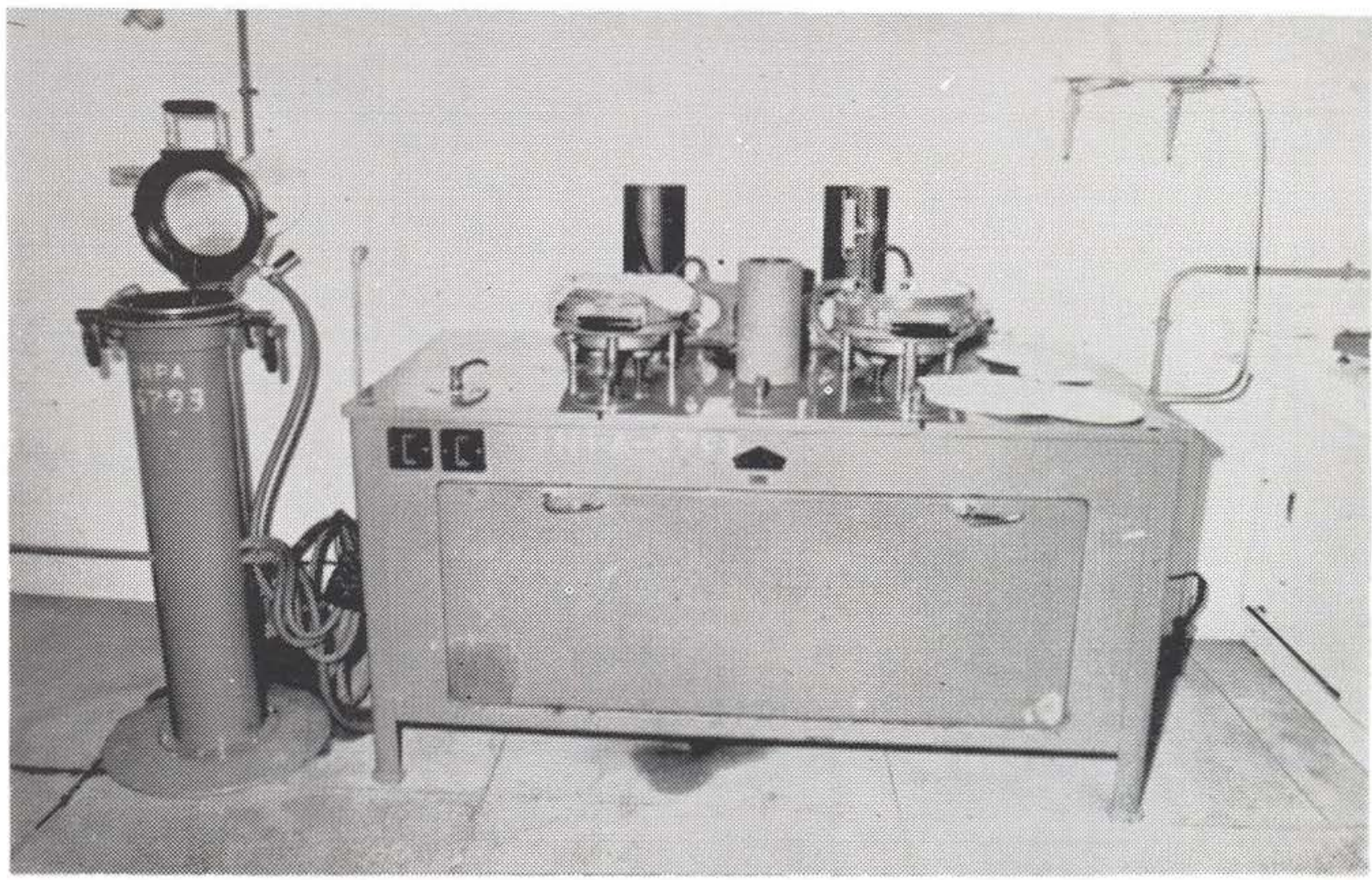

Fig. 8 - Máquina formadora de papel para ensaio de laboratório. Foto: J. Romulo 
TABELA N.॰ VII

Características das pastas alvejadas dos cozimentos soda/enxôfre do Pinus caribeae - var. hondurensis da região de Santarém, resultados interpolados a $45^{\circ}$ SR - Jokro e Bauer.

\begin{tabular}{|c|c|c|c|c|c|c|c|c|c|c|}
\hline $\begin{array}{l}\text { EQUIPA- } \\
\text { MENTO }\end{array}$ & $\begin{array}{l}\text { NO DE CO- } \\
\text { ZIMENTO }\end{array}$ & $\begin{array}{l}\text { PROCESSO } \\
\text { DE ALVE- } \\
\text { JAMENTOS }\end{array}$ & $\begin{array}{l}\text { AUTO- } \\
\text { RUPTURA } \\
\mathbf{m}\end{array}$ & $\begin{array}{l}\text { RASGO } \mathrm{g} \\
\text { Por } \\
100 \mathrm{~g} / \mathrm{m}^{2}\end{array}$ & $\begin{array}{c}\text { ESTOURO } \\
\mathrm{Kg} / \mathrm{cm}^{2} \\
100 \mathrm{~g} / \mathrm{m}^{2}\end{array}$ & $\begin{array}{l}\text { DOBRAS } \\
\text { DUPLAS } \\
\text { N.0 }\end{array}$ & $\begin{array}{l}\text { POROSI- } \\
\text { DADE } \\
\text { Seg/100 ce }\end{array}$ & $\begin{array}{l}\text { LISURA } \\
\text { Seg/50 cc }\end{array}$ & $\begin{array}{c}\text { MACIEZ } \\
\mathrm{Seg} / 100 \mathrm{cc}\end{array}$ & $\begin{array}{l}\text { ALONGA- } \\
\text { MENTO } \\
\%\end{array}$ \\
\hline \multirow{12}{*}{ Jokro } & \multirow{2}{*}{190} & $\mathrm{CEHH}$ & 5.277 & 86 & 2,0 & 34 & 25 & 20 & 25 & 1,0 \\
\hline & & CEDPD & 6.135 & 123 & 2,0 & 327 & 11 & 16 & 31 & 1,4 \\
\hline & \multirow{2}{*}{193} & CEHH & 2.910 & 80 & 0,0 & 3 & $\begin{array}{l}\text { Extremamente } \\
\text { Impermeável }\end{array}$ & 13 & 31 & 1,0 \\
\hline & & CEDPD & 5.497 & 108 & 2,0 & 97 & 17 & 17 & 27 & 4,0 \\
\hline & \multirow{2}{*}{191} & CEHH & 3.536 & 86 & 0,0 & 6 & $\begin{array}{l}\text { Extremamente } \\
\text { Impermeável }\end{array}$ & 20 & 33 & 1,0 \\
\hline & & CEDPD & 6.101 & 112 & 2,0 & 106 & 13 & 15 & 29 & 1,7 \\
\hline & \multirow[t]{2}{*}{194} & CEHH & 4.400 & 61 & 1,0 & 18 & $\begin{array}{l}\text { Extremamente } \\
\text { Impermeável }\end{array}$ & 20 & 27 & 1,0 \\
\hline & & CEDPD & 7.426 & 109 & $1,4:$ & 339 & 57 & 41 & 27 & 1,4 \\
\hline & \multirow[t]{2}{*}{195} & CEHH & 4.365 & 62 & 1,0 & 11 & $\begin{array}{l}\text { Extremamente } \\
\text { Impermeável }\end{array}$ & 18 & 29 & 1,4 \\
\hline & & CEDPD & 6.834 & 103 & 3,4 & 325 & $21 \%$ & 20 & 25 & 1,5 \\
\hline & \multirow[t]{2}{*}{196} & $\mathrm{CEHH}$ & 4.786 & 61 & 1,0 & 9 & $\begin{array}{l}\text { Extremamente } \\
\text { Impermeável }\end{array}$ & 20 & 28 & 1,3 \\
\hline & & CEDPD & 6.417 & 99 & 3,0 & 153 & 41 & 17 & 26 & 1,3 \\
\hline \multirow{12}{*}{ Bauer } & \multirow{2}{*}{190} & CEHH & 3.324 & 126 & 0,0 & 46 & $\begin{array}{l}\text { Extremamente } \\
\text { Impermeável }\end{array}$ & 10 & 45 & 1,0 \\
\hline & & CEDPD & 4.548 & 198 & 2,4 & 247 & 16 & 22 & 29 & 2,0 \\
\hline & \multirow{2}{*}{293} & CEHH & 3.040 & 78 & 0,0 & 5 & $\begin{array}{l}\text { Extremamente } \\
\text { Impermeável }\end{array}$ & 16 & 37 & 1,0 \\
\hline & & CEDPD & 3.984 & 136 & 2,6 & 397 & 89 & 16 & 29 & 1,6 \\
\hline & \multirow[t]{2}{*}{191} & CEHH & 3.252 & 96 & 0,0 & 4 & $\begin{array}{l}\text { Extremamente } \\
\text { Impermeável }\end{array}$ & 17 & 37 & 1,0 \\
\hline & & CEDPD & 5.039 & 137 & 2,0 & 105 & $\begin{array}{l}\text { Extremamente } \\
\text { Impermeável }\end{array}$ & 25 & 36 & 1,5 \\
\hline & \multirow[t]{2}{*}{194} & $\mathrm{CEHH}$ & 5.907 & 78 & 2,0 & 34 & $\begin{array}{l}\text { Extremamente } \\
\text { Impermeável }\end{array}$ & 19 & 25 & 1,1 \\
\hline & & CEDPD & 4.882 & 172 & 3,1 & 434 & 152 & 38 & 31. & 1,4 \\
\hline & \multirow[t]{2}{*}{195} & $\mathrm{CEHH}$ & 4.678 & 90 & 1,0 & 11 & 33 & 18 & 30 & 1,0 \\
\hline & & CEDPD & 5.566 & 133 & 2,5 & 264 & $\begin{array}{l}\text { Extremamente } \\
\text { Impermeável }\end{array}$ & 51 & 28 & 1,3 \\
\hline & \multirow{2}{*}{196} & CEHH & 4.423 & 81 & 1,4 & 16 & 9 & 13 & 30 & 1,0 \\
\hline & & CEDPD & 5.419 & 139 & 2,3 & 222 & 45 & 21 & 28 & 1,2 \\
\hline
\end{tabular}




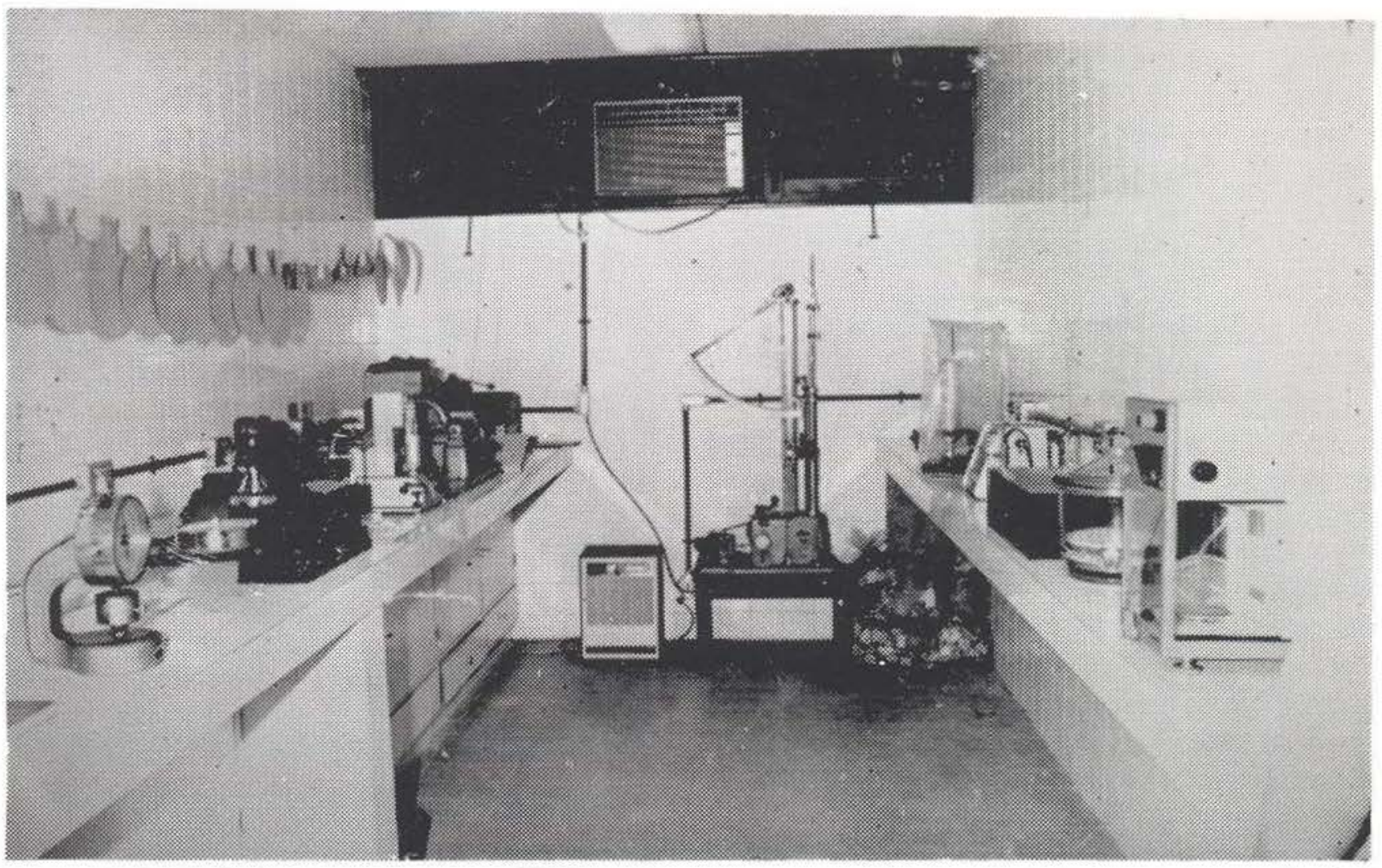

Fig. 9 - Sala de testes físico-mecânicos. Foto: J. Romulo

Para as pastas alvejadas as características de resistência diminuiram a medida que cresceu a percentagem de soda utilizada nos processos de cocção. Em contra partida as polpas alvejadas pelo processo C.E.D.P.D., quase que não sofreram degradaçãc, principalmente quando se compara com as quedas de resistência das características dos papéis provenientes do alvejamento pelo processo C.E.H.H

De um modo geral as pastas cruas e alvejadas se caracterizaram por uma boa resistên- cia ao rasgo (índice de rasgo superior a 100), a Auto-ruptura, Estouro e Dobras-duplas são suficientes, inas inferiores às dos resinosos utilizados pela indústria papeleira do sul da Europa.

\section{OUTROS PROCEDIMENTOS DE FABRICAÇÃO}

A amostra de Pinus caribeae foi testada pelo procedimento Soda e Monosulfite (N.S. S.C.), visando a obtenção de pastas de alto rendimento.

\section{TABELA N.० VIII}

Resultado do cozimento a soda do Pinus caribeae - var. hondurensis da região de Santarém.

\begin{tabular}{|c|c|c|c|c|c|c|c|}
\hline \multirow[b]{2}{*}{$\begin{array}{c}\text { Número } \\
\text { de } \\
\text { cozimento }\end{array}$} & \multirow[b]{2}{*}{ Patamar } & \multirow[b]{2}{*}{$\underset{\%}{\mathrm{NaOH}}$} & \multicolumn{2}{|c|}{ Rendimento } & \multirow[b]{2}{*}{$\underset{\mathrm{g} / 1}{\mathrm{NaOH}}$} & \multirow[b]{2}{*}{$\begin{array}{l}\text { "Photovolt" } \\
\text { Alvura da } \\
\text { pasta }\end{array}$} & \multirow[b]{2}{*}{$\begin{array}{l}\text { Indice de } \\
\mathrm{KMnO}_{4} \\
(80 \mathrm{cc})\end{array}$} \\
\hline & & & $\begin{array}{c}\text { Bruto } \\
\%\end{array}$ & $\begin{array}{c}\text { Depurado } \\
\%\end{array}$ & & & \\
\hline 201 & $1 \mathrm{~h} 30^{\prime}-170^{\circ} \mathrm{C}$ & 26 & 55,39 & 55,30 & 7,6 & 27 & 51,56 \\
\hline
\end{tabular}




\section{TRATAMENTO A SODA}

Para a obtenção de pasta crua, aplicou-se a mesma metodologia utilizada na obtenção das polpas Soda/Enxofre; sendo realizado um único ensaio de cocção com duas horas de montagem e $1 \mathrm{~h} 30^{\circ}$ de patamar à temperatura de $170^{\circ} \mathrm{C}$.

O resultado deste ensaio está na Tabela n. ${ }^{\circ}$ VIII.

Pode-se tratar o Pinus caribeae com 26\% de $\mathrm{NaOH} /$ Madeira Seca sem acarretar taxa de rejeito proibitivo. A pasta obtida foi menos deslignificada do que as provenientes do processo Soda/Enxofre, nos mesmos parâmetros, atentando que houve urn maior consumo de soda por parte do procedimento tipo "Kraft".

$O$ rendimento caracteriza o tipo de celulose obtida como pasta semiquímica, com $n .^{\circ}$ de $\mathrm{KMnO}_{4}$ elevado, corresponde a baixo índice de deslignificação.

Este processo é menos satisfatório que o tratamento Soda/Enxofre. Entretanto, ele po- derá a rigor, constituir alternativa para os países em desenvolvimento que tenham dificuldade de obtenção de insumos como enxofre e sulfato.

\section{ALVEJAMENTo das pastas obtidas DO COZIMENTO À SODA}

A pasta proveniente do cozimento à Soda foi também alvejada pelos processos $\mathrm{CEHH}$ e CEDPD. O resultado deste estudo está na Tabela $n$. IX e X.

As considerações feitas para os alvejamentos das pastas Soda/Enxofre são válidas para a polpa obtida com o cozimento à Soda, exigindo a celulose obtida por este processo uma maior demanda de substâncias oxidantes do que as solicitadas pelas pastas derivadas do processo Soda/Enxofre, nas mesmas condições de tratamento. O processo CEDPD foi mais satisfatório do que o procedimento $\mathrm{CEHH}$, proporcionando uma maior alvura e melhor estabilidade.

TABELA N.॰ IX

Resultado do branqueamento (CI - NaOH - CiONa) da pasta crua do cozimento à soda do Pinus caribeae - var. hondurensis.

\begin{tabular}{|c|c|c|c|c|c|c|c|c|c|}
\hline \multirow{2}{*}{$\begin{array}{l}\text { N. } \text { do co- }^{-} \\
\text {zimento }\end{array}$} & \multirow{2}{*}{$\begin{array}{c}\text { Cloração } \\
\text { Cloro con- } \\
\text { sumido } \\
\%\end{array}$} & \multicolumn{2}{|c|}{ Sodação } & \multicolumn{2}{|c|}{ 1. Fase-CIONa } & \multicolumn{2}{|c|}{ 2." Fase-CIONa } & \multirow{2}{*}{$\begin{array}{c}\text { "Photovolt" } \\
\text { Alvura da } \\
\text { pasta }\end{array}$} & \multirow{2}{*}{$\begin{array}{l}\text { Estabili- } \\
\text { dade da } \\
\text { alvura }\end{array}$} \\
\hline & & $\begin{array}{c}\mathrm{NaOH} \\
\text { Int. } \\
\%\end{array}$ & $\begin{array}{c}\mathrm{NaOH} \\
\text { Cons. } \\
\%\end{array}$ & $\begin{array}{c}\text { Cloro } \\
\text { Int. } \\
\%\end{array}$ & $\begin{array}{c}\text { Cloro } \\
\text { Cons. } \\
\%\end{array}$ & $\begin{array}{c}\text { Cloro } \\
\text { Int. } \\
\%\end{array}$ & $\begin{array}{c}\text { Cloro } \\
\text { Cons. } \\
\%\end{array}$ & & \\
\hline 201 & 4,2 & 4,0 & 4,0 & 4,0 & 3,8 & 0,5 & 0,3 & 88 & 81 \\
\hline
\end{tabular}

TABELA $\mathbf{N} \circ \mathbf{X}$

Resultado do branqueamento $\left(\mathrm{Cl}-\left(\mathrm{NaOH}-\mathrm{H}_{2} \mathrm{O}_{2}\right)-\mathrm{CH},-\mathrm{H}_{2} \mathrm{O}_{2}-\mathrm{ClO}_{2}\right)$ da pasta crua do cozimento à soda do Pinus caribeae - var. hondurensis.

\begin{tabular}{|c|c|c|c|c|c|c|c|c|c|c|c|c|c|}
\hline \multirow{2}{*}{$\begin{array}{c}\text { N.o } \\
\text { do cozi- } \\
\text { mento }\end{array}$} & \multirow{2}{*}{$\begin{array}{l}\text { CLORAÇÃo } \\
\begin{array}{c}\text { Cloro con- } \\
\text { sumido } \\
\%\end{array}\end{array}$} & \multicolumn{4}{|c|}{ SODAÇĀO OXIDANTE } & \multicolumn{2}{|c|}{ 3. ${ }^{\mathrm{a}}$ FASE-CIO } & \multicolumn{2}{|c|}{ 4. ${ }^{\mathrm{a}}$ FASE- $\mathrm{H}_{2} \mathrm{O}_{2}$} & \multicolumn{2}{|c|}{ 5. ${ }^{2}$ FASE-C1O } & \multirow{2}{*}{$\begin{array}{c}\begin{array}{c}\text { PHOTO- } \\
\text { VOLT }\end{array} \\
\begin{array}{c}\text { Alvura da } \\
\text { pasta }\end{array}\end{array}$} & \multirow{2}{*}{$\begin{array}{l}\text { ESTABILI- } \\
\text { DADE DA } \\
\text { ALVURA }\end{array}$} \\
\hline & & $\begin{array}{c}\mathrm{NaOH} \\
\text { Int. } \\
\%\end{array}$ & $\begin{array}{l}\mathrm{NaOH} \\
\text { Conss. } \\
\%\end{array}$ & $\begin{array}{l}\mathrm{H}_{2} \mathrm{O}_{2} \\
\text { Int. } \\
\%\end{array}$ & $\begin{array}{c}\mathrm{H}_{2} \mathrm{O}_{2} \\
\text { Cons } \\
\%\end{array}$ & $\begin{array}{l}\text { Cloro } \\
\text { Int. } \\
\%\end{array}$ & $\begin{array}{c}\text { Cloro } \\
\text { Cons. } \\
\%\end{array}$ & $\begin{array}{l}\mathrm{H}_{2} \mathrm{O}_{2} \\
\text { Int. } \\
\%\end{array}$ & $\begin{array}{c}\mathrm{H}_{2} \mathrm{O}_{2} \\
\text { Cons. } \\
\%\end{array}$ & $\begin{array}{c}\text { Cloro } \\
\text { Int. } \\
\%\end{array}$ & $\begin{array}{c}\text { Cloro } \\
\text { Cons. } \\
\%\end{array}$ & & \\
\hline 201 & 4,0 & 4,0 & 4,0 & 1 & 0,8 & 2,6 & 2,5 & 1 & 0,9 & 1,3 & 1,2 & 91 & 89 \\
\hline
\end{tabular}


CARACTERÍSTICAS DOS PAPÉIS DAS PASTAS CRUAS E ALVEJADAS, ORIGINÁRIAS DO PROCESSO À SODA.

Para a avaliação das características dos papéis das pastas cruas e alvejadas, procedeuse de maneira equivalente aos da pasta do processo químico, com uma diferença de que o refino foi efetuado somente no moinho Bauer, por tratar-se de pasta semiquímica, onde este equipamento é classicamente utilizado.

Os resultados podem ser vistos nas tabelas $\mathrm{N} \div \mathrm{S}$. XI E XII.

Em relação às pastas cruas, as resistências dos papéis foram inferiores aos da pasta processo Soda/Enxofre para as mesmas condições de cozimento.

Em análise comparativa (Ver Quadro II) dos dois processos evidencia que as qualidades dos papéis provenientes das pastas cruas e alvejadas Soda/Enxofre, são de uma qualidade superior ao do procedimento à Soda.

Como nos alvejamentos das polpas Soda/ Enxofre, o processo CEDPD mostrou-se mais convincente não só por proporcionar melhor alvura, como por não degradar o material e até propiciar ganhos em resistência.

\section{TrATAMENTo a monosulfite}

A amostra do Pinus caribeae foi tratada pelo processo N.S.S.C. (Sulfite Neutro), tamponada com carbonato de sódio. As condições de tratamento retidas foram as seguintes: 18\% e $24 \%$ de $\mathrm{Na}_{2} \mathrm{SO}_{3}, 6 \%$ e $8 \%$ de $\mathrm{Na}_{2} \mathrm{CO}_{3}$, respectivamente. A duração total dos cozimentos fol de 6 horas, com um patamar intermediário de $110^{\circ} \mathrm{C}$, por 55 minutos e um patamar final de 3 horas a $165^{\circ} \mathrm{C}$. A relação lixivia/madeira seca $=4,5 / 1$.

Os resultados dos tratamentos estão na tabela $n .^{\circ}$ XIii.

Os rendımentos em pastas são normais e característicos das pastas químico-mecânicas e se situaram acima de $70 \%$, havendo, no entanto, uma ligeira superioridade no rendimento para a amostra tratada com $24 \%$ de $\mathrm{Na}_{2} \mathrm{SO}_{3}$ e $8 \%$ de $\mathrm{Na}_{2} \mathrm{CO}_{3}$.

\section{TABELA N.॰ XI}

Característica da pasta crua do cozimento à soda do Pinus caribeae - var. hondurensis da região de Santarém, resultados interpolados a $45^{\circ} \mathrm{SR}$ - Moagem no Bauer

\begin{tabular}{|c|c|c|c|c|c|c|c|c|c|}
\hline $\begin{array}{l}\text { Equipa- } \\
\text { mento }\end{array}$ & $\begin{array}{l}\text { N. } \\
\text { de cozi- } \\
\text { mento }\end{array}$ & $\begin{array}{c}\text { Auto } \\
\text { ruptura } \\
\text { m }\end{array}$ & $\begin{array}{c}\text { Rasgo } \mathrm{g} \\
\text { Por } \\
100 \mathrm{~g} / \mathrm{m}^{2}\end{array}$ & $\begin{array}{r}\text { Estouro } \\
\mathrm{Kg} / \mathrm{cm}^{2} \\
100 \mathrm{~g} / \mathrm{m}^{2}\end{array}$ & $\begin{array}{c}\text { Dobras } \\
\text { Duplas } \\
\text { N.॰ }\end{array}$ & $\begin{array}{l}\text { Porosi- } \\
\text { dade } \\
\text { Seg } / 100 \mathrm{cc}\end{array}$ & $\begin{array}{r}\text { Lisura } \\
\text { Seg/50ce }\end{array}$ & $\begin{array}{c}\text { Maciez } \\
\text { Seg/100c }\end{array}$ & $\begin{array}{c}\text { Alonga- } \\
\text { mento } \\
\%\end{array}$ \\
\hline BAUER & 201 & 4.409 & 124 & 1,9 & 42 & 61 & 12 & 47 & 1,0 \\
\hline
\end{tabular}

\section{TABELA N.॰ XII}

Carac!erística da pasta alvejada do cozimento à soda do Pinus caribeae - var. hondurensis da região de Santarém, resultados interpolados a $45^{\circ} \mathrm{SR}$ - Moagem no Bauer.

\begin{tabular}{|c|c|c|c|c|c|c|c|c|c|c|}
\hline $\begin{array}{l}\text { Equipa- } \\
\text { mento }\end{array}$ & $\begin{array}{l}\text { N.॰ } \\
\text { de cozi- } \\
\text { mento }\end{array}$ & $\begin{array}{l}\text { Processo } \\
\text { de alve- } \\
\text { mentos }\end{array}$ & $\begin{array}{c}\text { Auto } \\
\text { ruptura } \\
\mathbf{m}\end{array}$ & $\begin{array}{c}\text { Rasgo } \mathrm{g} \\
\text { Por } \\
100 \mathrm{~g} / \mathrm{m}^{2}\end{array}$ & $\begin{array}{c}\text { Estouro } \\
\mathrm{Kg} / \mathrm{cm}^{2} \\
100 \mathrm{~g} / \mathrm{m}^{2}\end{array}$ & $\begin{array}{c}\text { Dobras } \\
\text { Duplas } \\
\text { N.॰ }\end{array}$ & $\begin{array}{l}\text { Porosi- } \\
\text { dade }\end{array}$ & $\begin{array}{c}\text { Lisura } \\
\text { Seg/50cc }\end{array}$ & Maciez & $\begin{array}{c}\text { Alonga- } \\
\text { mento } \\
\%\end{array}$ \\
\hline \multirow{2}{*}{$\begin{array}{c}n \\
\text { BAUER }\end{array}$} & \multirow{2}{*}{201} & $\mathrm{CEHH}$ & 4.185 & 70 & 1,0 & 5 & 23 & 27 & 31 & 1,0 \\
\hline & & CEDPD & 5.356 & 113 & 2,6 & 212 & 57 & 37 & 29 & 1,3 \\
\hline
\end{tabular}




\section{QUADRO II}

Quadro comparativo das características de resistências das pastas cruas e alvejadas dos processos soda/enxofre e soda refinadas em moinho Bauer.

\section{PASTAS CRUAS}

\begin{tabular}{|c|c|c|c|c|c|c|c|c|c|}
\hline $\begin{array}{l}\text { Pro. } \\
\text { cessos }\end{array}$ & $\begin{array}{c}\text { N.o } \\
\text { do cozi- } \\
\text { mento }\end{array}$ & $\begin{array}{c}\text { Auto } \\
\text { ruptura } \\
\text { m }\end{array}$ & $\begin{array}{c}\text { Rasgo } \mathrm{g} \\
\text { Por } \\
100 \mathrm{~g} / \mathrm{m}^{2}\end{array}$ & $\begin{array}{r}\text { Estouro } \\
\mathrm{Kg} \mathrm{cm} \mathrm{cm}^{2} \\
100 \mathrm{~g} / \mathrm{m}^{2}\end{array}$ & $\begin{array}{c}\text { Dobras } \\
\text { Duplas } \\
\text { N.॰ }\end{array}$ & $\begin{array}{c}\text { Porosi. } \\
\text { dade } \\
\text { Seg } / 100 \mathrm{cc}\end{array}$ & $\begin{array}{l}\text { Lisura } \\
\text { Seg/50 ce }\end{array}$ & $\begin{array}{c}\text { Maciez } \\
\text { Seg/100 ce }\end{array}$ & $\begin{array}{c}\text { Alongamento } \\
\%\end{array}$ \\
\hline Soda & 201 & 4.409 & 124 & 1,9 & 42 & 6,1 & 12 & 47 & 1,0 \\
\hline $\begin{array}{l}\text { Soda/enxofre } \\
26 \% 170^{\circ} \mathrm{C}\end{array}$ & 191 & 6.258 & 155 & 3,0 & 438 & 74 & 29 & 32 & 1,0 \\
\hline $\begin{array}{l}\text { Soda/enxofre } \\
26 \% 155^{\circ} \mathrm{C}\end{array}$ & 194 & 5.492 & 1.556 & 2,0 & 517 & 45 & 20 & 41 & 1,5 \\
\hline
\end{tabular}

PASTAS ALVEJADAS

\begin{tabular}{|c|c|c|c|c|c|c|c|c|c|c|}
\hline $\begin{array}{c}\text { Pro. } \\
\text { cessos }\end{array}$ & $\begin{array}{c}\text { N. } \\
\text { do cozi- } \\
\text { mento }\end{array}$ & $\begin{array}{l}\text { Tipo de } \\
\text { alveja- } \\
\text { mentos }\end{array}$ & $\begin{array}{c}\text { Auto } \\
\text { ruptura } \\
\text { m }\end{array}$ & $\begin{array}{c}\text { Rasgo } \mathrm{g} \\
\text { Por } \\
100 \mathrm{~g} / \mathrm{m}^{2}\end{array}$ & 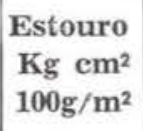 & $\begin{array}{c}\text { Dobras } \\
\text { Duplas } \\
\text { N.॰ }\end{array}$ & $\begin{array}{r}\text { Porosidade } \\
\text { Seg/100cc }\end{array}$ & $\begin{array}{r}\text { Lisura } \\
\text { Seg/50 ce }\end{array}$ & $\begin{array}{c}\text { Maciez } \\
\text { Seg/100 cc }\end{array}$ & $\begin{array}{c}\text { Alonga- } \\
\text { mento } \\
\%\end{array}$ \\
\hline \multirow{2}{*}{ Soda } & \multirow{2}{*}{201} & CEHH & 4.185 & 70 & 1,0 & 5 & 25 & 27 & 31 & 1,0 \\
\hline & & CEDPD & 5.356 & 113 & 2,5 & 212 & 57 & 37 & 29 & 1,3 \\
\hline \multirow{2}{*}{$\begin{array}{l}\text { Soda/en- } \\
\text { xofre } \\
26 \% \\
170^{\circ} \mathrm{C}\end{array}$} & \multirow{2}{*}{191} & CEHH & 3.252 & 96 & 0,0 & 4 & $\begin{array}{l}\text { Extremamente } \\
\text { Impermeável } \\
\end{array}$ & 17 & $3 i$ & 1,0 \\
\hline & & CEDPD & 5.039 & 96 & 2,0 & 105 & $\begin{array}{l}\text { Extremamente } \\
\text { Impermeável }\end{array}$ & 25 & 36 & 1,5 \\
\hline \multirow{2}{*}{$\begin{array}{l}\text { Soda/en- } \\
\text { xofre } \\
26 \% \\
155^{\circ} \mathrm{C}\end{array}$} & \multirow{2}{*}{194} & CEHH & 5.907 & 78 & 2,0 & 34 & $\begin{array}{l}\text { Extremamente } \\
\text { Impermeável } \\
\end{array}$ & 19 & 25 & 1,1 \\
\hline & & CEDPD & 4.882 & 17ః & 3,1 & 434 & 152 & 38 & 31 & 1,4 \\
\hline
\end{tabular}

As quantidades de $\mathrm{SO}_{2}$ livre e combinado nas lixivias residuais não chegam a serem significantes, que tornem as condições retidas para o tratamento proibitivas em termos de realizaçäo industrial.

As alvuras das pastas cruas foram superiores às dos processos Químico e Semiquico. com melhor resultado para a polpa do cozimento n. 202.

Os N's. de $\mathrm{KMnO}_{4}$ foram altos e bem peculiares aos das pastas de alto rendimento.
De um modo geral os resultados das condições retidas, correspondentes ao n. 203 foram superiores aos observados para as condiçōes de tratamento n. 202 . Por outro lado, as pastas obtidas por este processo podem ser utilizadas eventualmente no estado "cru", uma vez que sob a forma alvejada se tornariam inconvenientes, em decorrência do considerável consumo de cloro que seria exigido na ob. tenção de u'a maior alvura. 
TABELA N.॰ XIII

Resultados dos cozimentos monosulfite $\left(\mathrm{SO}_{3} \mathrm{Na}_{2}-\mathrm{CO}_{3} \mathrm{Na}_{2}\right)$ do Pinus caribeae - var. hondurensis da região de Santarém.

\begin{tabular}{|c|c|c|c|c|c|c|c|c|c|}
\hline \multirow{2}{*}{$\begin{array}{l}\text { N. } \\
\text { de cozi- } \\
\text { mento }\end{array}$} & \multirow[b]{2}{*}{ Patamar } & \multirow[b]{2}{*}{$\begin{array}{c}\mathrm{SO}_{3} \mathrm{Na}_{2} \\
\%\end{array}$} & \multirow[b]{2}{*}{$\begin{array}{c}\mathrm{CO}_{3} \mathrm{Na}_{2} \\
\%\end{array}$} & \multicolumn{2}{|c|}{ Rendimento } & \multicolumn{2}{|c|}{$\mathrm{SO}_{2}$} & \multirow{2}{*}{ 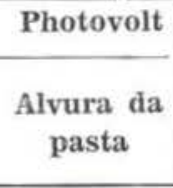 } & \multirow{2}{*}{$\begin{array}{c}\text { Indice de } \\
\mathrm{KMnO}_{4} \\
(80 \mathrm{cc})\end{array}$} \\
\hline & & & & $\begin{array}{c}\text { Bruto } \\
\%\end{array}$ & $\begin{array}{c}\text { Depu- } \\
\text { rado } \\
\%\end{array}$ & $\begin{array}{c}\text { Livre } \\
\text { g }\end{array}$ & $\begin{array}{c}\text { Combi- } \\
\text { nado } \\
\mathrm{g}\end{array}$ & & \\
\hline 202 & \multirow{2}{*}{$3 \mathrm{~h}-165^{\circ} \mathrm{C}$} & 18 & 6 & 73,6 & 73,6 & 0,042 & 0,044 & 44 & 56 \\
\hline 203 & & 24 & 8 & 78,5 & 78,5 & 0,072 & 0,073 & 45 & 54 \\
\hline
\end{tabular}

\section{CLAREAMENTO DAS PASTAS}

DO PROCESSO MONOSULFITE

As pastas de alto rendimento originárias do processo N.S.S.C. foram clareadas com pcróxido de hidrogênio com adição crescente, a fim de verificar-se o comportamento evolutivo das alvuras frente a estes clareantes.

Os resultados estăo na Tabela $n$. $^{\circ}$ XIV.

Relacionando-se o consumo de reagentes com as alvuras obtidas, observa-se que com $2 \%$ de $\mathrm{H}_{2} \mathrm{O}_{2}$ não houve alterações nas alvuras. Com $5 \%$ de clareantes ganhou-se em alvura a ordem de uma unidade para o tratamento com $24 \%$ de $\mathrm{Na}_{2} \mathrm{SO}_{3}$ e $8 \%$ de $\mathrm{Na}_{2} \mathrm{CO}_{3}$, permanecendo 0 "Photovolt" da pasta do cozimento n. 202 constante. Com $10 \%$ de peróxido aplicado os ganhos em alvura não foram relevantes em relação ao consumo de reagentes. Estas observações nos fornecem as seguintes conclusões:

a) As pastas oferecem dificuldades de serem clareadas por este tipo de tratatamento, principalmente a obtida com $18 \% \mathrm{Na}_{2} \mathrm{SO}_{3}$ e $6 \% \mathrm{Na}_{2} \mathrm{CO}_{3}$ :

b) No balanceamento dos ganhos em alvura e demanda de reagentes a melhor condição verificada foi a de $5 \%$ de $\mathrm{H}_{2} \mathrm{O}_{2}$ aplicado;

c) $\mathrm{O}$ clareamento com $10 \%$ de $\mathrm{H}_{2} \mathrm{O}_{2}$ apresenta inconvenientes caracterizados pelo alto consumo de reagentes e baixos ganhos em alvura.

\section{TABELA N.ค XIV}

Resultados dos clareamentos $\left(\mathrm{H}_{2} \mathrm{O}_{2}\right)$ das pastas cruas dos cozimentos monosulfite do Pinus caribeae - var. hondurensis.

\begin{tabular}{|c|c|c|c|c|c|c|c|c|c|}
\hline \multirow[b]{2}{*}{$\begin{array}{l}\text { N. de co- } \\
\text { zimento }\end{array}$} & \multicolumn{3}{|c|}{ 1. Ensaio: $\mathrm{H}_{2} \mathrm{U}_{2}$} & \multicolumn{3}{|c|}{ 2. Ensaio: $\mathrm{H}_{2} \mathrm{O}_{2}$} & \multicolumn{3}{|c|}{ 3. Ensaio: $\mathrm{H}_{2} \mathrm{O}_{2}$} \\
\hline & $\begin{array}{c}\mathrm{H}_{2} \mathrm{O}_{2} \\
\text { Int. } \\
\%\end{array}$ & $\begin{array}{c}\mathrm{H}_{2} \mathrm{O}_{2} \\
\text { Cons. } \\
\%\end{array}$ & $\begin{array}{c}\text { Protovolt } \\
\text { Alvura da } \\
\text { pasta }\end{array}$ & $\begin{array}{c}\mathrm{H}_{2} \mathrm{O}_{2} \\
\text { Int. } \\
\%\end{array}$ & $\begin{array}{c}\mathrm{H}_{2} \mathrm{O}_{2} \\
\text { Cons. } \\
\%\end{array}$ & $\begin{array}{c}\text { Protovolt } \\
\text { Alvura da } \\
\text { pasta }\end{array}$ & $\begin{array}{c}\mathrm{H}_{2} \mathrm{O}_{2} \\
\text { Int. } \\
\%\end{array}$ & $\begin{array}{c}\mathrm{H}_{2} \mathrm{O}_{2} \\
\text { Cons. } \\
\%\end{array}$ & $\begin{array}{c}\text { Protovolt } \\
\text { Alvura da } \\
\text { pasta }\end{array}$ \\
\hline 202 & 2,0 & 2,0 & 46 & 5,0 & 5,0 & 46 & 10,0 & 10,0 & 47 \\
\hline 203 & 2,0 & 2,0 & 47 & 5,0 & 5,0 & 48 & 10,0 & 10,0 & 48 \\
\hline
\end{tabular}


CARACTERISTICAS DAS PASTAS CRUAS E CIAREADAS DO PROCEDIMENTO MONOSULFITE

Os cavacos impregnados foram desfibrados em Desfibrador de Disco Sprout Waldron Mod - D2 - 202, Disco n. ${ }^{\circ} 17.804$, potência do motor $40 \mathrm{C} . \mathrm{V}$. com afastamento dos discos de 30 medidas de polegadas. Não foi possível medir a energia de desfibragem, em decorrência da instrumentação nâo estar equipada no momento da realização do ensaio com o vatímetro necessário à mensuração.

As pastas desfibradas foram refinadas em moinho Bauer a $45^{\circ} \mathrm{SR}$ e para a obtenção dos corpos de prova e realização dos ensaios físico-mecânicos procedeu-se de maneira equiva- lente aos efetuados para os estudos procedentes.

Os resultados dos ensaios estão nas Tabelas n`s. XV e XVI.

Tanto para as pastas cruas como para as polpas clareadas, os valores provenientes do tratamento n. 203 foram mais promissores, cáracterizados por um alto índice de rasgo, observado também no estudo químico e semiquímico.

No conjunto as características físico-mecânicas das pastas cruas e clareadas foram baixas, com exceção do rasgo, que dá perspectiva desta madeira ser utilizada na fabricação de pastas, visando a obtenção de papéis de embalagem de boa qualidade.

\section{TABELA N.ค XV}

Características das pastas cruas dos cozimentos monosulfite do Pinus caribeae - var. hondurensis da região de Santarém. Resultados interpolados a $45^{\circ}$ SR - Moagem no Bauer.

\begin{tabular}{|c|c|c|c|c|c|c|c|c|c|}
\hline $\begin{array}{l}\text { Equipa- } \\
\text { mento }\end{array}$ & $\begin{array}{l}\text { N. }{ }^{\circ} \\
\text { de cozi- } \\
\text { mento }\end{array}$ & $\begin{array}{c}\text { Auto } \\
\text { ruptura } \\
\text { m }\end{array}$ & $\begin{array}{c}\text { Rasgo } \mathrm{g} \\
\text { Por } \\
100 \mathrm{~g} / \mathrm{m}^{2}\end{array}$ & $\begin{array}{l}\text { Estouro } \\
\mathrm{Kg} / \mathrm{cm}^{2} \\
100 \mathrm{~g} / \mathrm{m}^{2}\end{array}$ & $\begin{array}{c}\text { Dobras } \\
\text { Duplas } \\
\text { N.॰ }\end{array}$ & $\begin{array}{l}\text { Porosidade } \\
\text { Seg/100cc }\end{array}$ & $\begin{array}{c}\text { Lisura } \\
\text { Seg/50ce }\end{array}$ & $\begin{array}{l}\text { Maciez } \\
\text {;eg/100cc }\end{array}$ & $\begin{array}{c}\text { Alonga- } \\
\text { mento } \\
\%\end{array}$ \\
\hline \multirow{2}{*}{ Bauer } & 202 & 3.462 & 99 & 0 & 10 & 7,0 & 9,7 & 33 & 0,9 \\
\hline & 203 & 3.889 & 100 & 8,7 & 25 & 217 & 9,0 & 21 & 0,8 \\
\hline
\end{tabular}

TABELA N.० XVI

Características das pastas clareadas dos cozimentos monosulfite do Pinus caribeae - var. hondurensis da região de Santarém. Resultados interpolados a $45^{\circ} \mathrm{SR}-$ Mvagem no Bauer.

\begin{tabular}{|c|c|c|c|c|c|c|c|c|c|c|}
\hline $\begin{array}{l}\text { Equipa- } \\
\text { mento }\end{array}$ & $\begin{array}{l}\text { N.o } \\
\text { de cozi- } \\
\text { mento }\end{array}$ & $\begin{array}{c}\text { Processo } \\
\text { de clarea- } \\
\text { mento }\end{array}$ & $\begin{array}{c}\text { Auto } \\
\text { ruptura } \\
\mathbf{m}\end{array}$ & $\begin{array}{c}\text { Rasgo } \mathrm{g} \\
\text { Por } \\
100 \mathrm{~g} / \mathrm{m}^{2}\end{array}$ & $\begin{array}{r}\text { Estouro } \\
\mathrm{Kg} / \mathrm{cm}^{2} \\
100 \mathrm{~g} / \mathrm{m}^{2}\end{array}$ & $\begin{array}{c}\text { Dobras } \\
\text { Duplas } \\
\text { N.。 }\end{array}$ & $\begin{array}{l}\text { Porosidade } \\
\text { Seg/100ce }\end{array}$ & $\begin{array}{c}\text { Lisura } \\
\text { Jeg/50cc }\end{array}$ & $\begin{array}{c}\text { Maciez } \\
\text { ieg/160cc }\end{array}$ & $\begin{array}{c}\text { Alonga- } \\
\text { mento } \\
\%\end{array}$ \\
\hline \multirow{2}{*}{ Bauer } & 202 & \multirow{2}{*}{$\mathrm{H}_{2} \mathrm{O}_{2}$} & 2.836 & 97 & 1,3 & 25 & $\begin{array}{l}\text { Extremamente } \\
\text { Impermeável }\end{array}$ & 8,0 & 35 & 0,7 \\
\hline & 203 & & $3.43 \eta$ & 121 & 1,0 & 100 & 164 & 12 & 33 & 0,8 \\
\hline
\end{tabular}




\section{TRATAMENTO MECÃNICO}

Na opinião de Vilars (1975) a pasta Mecânica é a "Gata Borralheira" $\left({ }^{5}\right)$ da indústria de celulose e papel. Apresenta algumas vezes impurezas, que restam do seu processo de fabricação. E sensível aos raios solares, o que Ihe confere pouca resistência, mesmo clarificada não atinge os níveis de alvura das pastas químicas branqueadas.

No plano comercial é a desconfiança dos compradores, os quais só apreciam as resistências e as alvuras das pastas nobres, mesmo se estas quaiidades forem supérfluas, penalizando os fabricantes, quando suspeitam alguns traços de impurezas (IBID). Entretanto, sua grande vantagem é o seu procedimento de fabricação, que propicia a utilização quase total; da madeira a poluição é mínima, quando comparada com as celuloses obtidas por pro- cesso químico; as suas instalações exigem pouco espaço e menos investimentos, podendo ser eventualmente integradas em qualquer unidade de fabricação. Os papéis por ela fornecidos possuem uniformidade na espessura, boa capacidade e estabilidade ao calor, conservando-se bem ao abrigo da luz; o seu preço de custo é incomparável em relação ao das outras pastas (cerca de $60 \%$ menos).

Considerando as idéias de Vilars, e o "deficit" crescente do país neste tipo de matériaprima (ver quadro III) e a importância que os plantios artificiais de resinosos tropicais poderão significar em termos de suprimento para esta demanda insatisfeita, realizou-se ensaios com a amostra de Pinus caribeae, visando a obtenção de pastas triturada.

Assim procedendo, a madeira foi transformada em cavacos com dimensões aproximadas dos de palitos de fósforos, obtendo-se

QUADRO N.॰ III

Brasil - Balanço entre consumo e oferta para o mercado interno de pasta mecânica $-1974 / 80$.

(Em $1.000 \mathrm{t})$

\begin{tabular}{c|c|c|c}
\hline \multirow{2}{*}{ ANOS } & \multicolumn{2}{|c}{ PASTA MECANICA } & \\
\cline { 2 - 4 } & OFERTA & CONSUMO & SALDO \\
\hline 1974 & 174 & 378 & -204 \\
\hline 1975 & 174 & 415 & -241 \\
\hline 1976 & 174 & 445 & -271 \\
\hline 1977 & 174 & 480 & -349 \\
\hline 1978 & 181 & 530 & -414 \\
\hline 1980 & 181 & 595 & -549 \\
\hline
\end{tabular}

FONTE; APFPC - CDI - BNDE - Programa Nacional de Celulose e Pape' - Conselho de Desenvolvimento Econômico.

(5) - Personagem da literatura infantil.

Essência papeleira... 
cerca de $200 \mathrm{~g}$ do material por ensaio realizado. Em seguida os cavacos foram submersos em água por 12 horas e submetidos aos testes de fabricaçăo em desfibrador Sprout Waldron, Mod. D2 - 202, Potência de desfibragem de $40 \mathrm{CV}$, Disco n. 17.804 . Inicialmente o equipamento operou com os discos afastados de 30 unidades de polegadas, para se obter os "Choucroutes " $\left({ }^{\circ}\right)$.

Posteriormente, na obtenção das pastas, o afastamento dos discos foi da ordem de 5 unidades de polegadas. Com o mesmo afastamento procedeu-se o refino da pasta a uma consistência de $2.5 \%$, com passagem sucessivas até a obtenção de um grau ${ }^{\circ} \mathrm{SR}$ superior a 50 . Obteve-se folhas de ensaio com uma gramatura aproximada de $100 \pm 20$ $\mathrm{g} / \mathrm{m}^{2}$. para avaliação das resistências. Os resultados obtidos estão na Tabela N.$^{\circ}$ XVII.
As qualidades das resistências em termo de valores absolutos são inferiores aos apresentados pela madeira mais tradicional de fabricação de pasta mecânica a Epicea obtida industrialmente. Entretanto, vale realçar que com exceção do estouro e das dobras, cujas resistências foram nulas, os demais resultados são encorajantes, considerando-se que a fabricação deste tipo de pasta em laboratório é extremamente mais dificil do que em escala industrial, em decorrência da pequena quantidade de material que é utilizado. Por outro lado, os resultados obtidos correspondem a um grau de refino de $51{ }^{\circ} \mathrm{SR}$, o que é pouco para uma pasta mecânica. Melhores resultados poderão ser atingidos à medida que se aumentar o grau de engorda da pasta. Como este en. saio foi uma primeira aproximação e que muito nos resta a pesquisar neste campo, pode-se considerar os resultados obtidos de um modo geral como satisfatório.

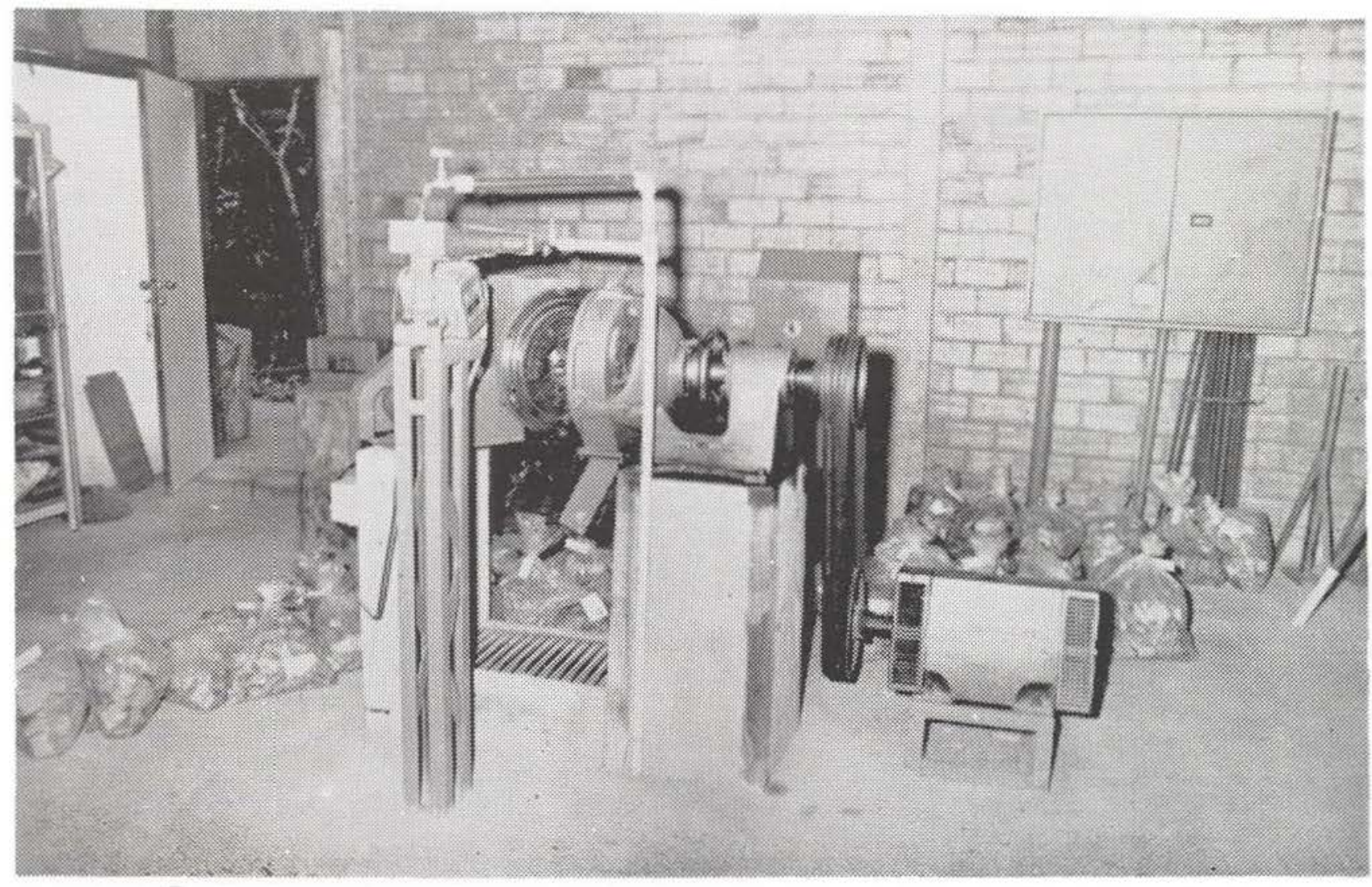

Fig. 10 - Sprout Waldron para obtenção de pasta me zânica. Foto: J. Romulo

(6) - Expressão francesa incorporada ao nosso linguajar técnico e significa madeira parcialmente triturada. 
TABELA N.॰ XVII

Característica da pasta mecânica do Pinus caribeae - Var. hondurensis da região de Santarém a $51^{\circ}$ SR.

\begin{tabular}{l|c|c|c|c|c|c|c|c|c}
\hline Essência & $\begin{array}{c}\text { Auto } \\
\text { ruptura } \\
\mathbf{m}\end{array}$ & $\begin{array}{c}\text { Rasgog } \\
\text { Por } \\
\mathbf{1 0 0 g / m ^ { 2 }}\end{array}$ & $\begin{array}{c}\text { Estouro } \\
\mathbf{K g} / \mathbf{c m}^{2} \\
\mathbf{1 0 0 g} / \mathbf{m}^{2}\end{array}$ & $\begin{array}{c}\text { Dobras } \\
\text { Duplas } \\
\mathbf{N} .0\end{array}$ & $\begin{array}{c}\text { Porosidade } \\
\text { Seg/100cc }\end{array}$ & $\begin{array}{c}\text { Lisura } \\
\text { Seg/50 cc }\end{array}$ & $\begin{array}{c}\text { Maciez } \\
\text { Seg/100 cc }\end{array}$ & $\begin{array}{c}\text { Alonga- } \\
\text { mento }\end{array}$ & $\begin{array}{c}\text { Photovolt } \\
\text { Alvura da } \\
\text { Pasta }\end{array}$ \\
\hline $\begin{array}{l}\text { Pinus } \\
\text { caribeae } \\
\text { madeira } \\
\text { verde }\end{array}$ & 2.897 & 15,0 & 0,0 & 0,0 & $\begin{array}{l}\text { Extremamente } \\
\text { poroso }\end{array}$ & 4,0 & 52,0 & 0,0 & 55 \\
\hline
\end{tabular}

\section{CONCLUSÃO}

As pesquisas levadas a efeito, caracterizaram as diversas pastas de Pinus caribeae Var. hondurensis na Amazônia, como susceptíveis de fornecerem papéis, se não de uma qualidade superior aos resinosos do hemisfério norte, porém comparáveis aos Pinus tropicais, que vem sendo utilizado em vários países em viạs de desenvolvimento. Justificando, portanto, no ponto de vista papeleiro, os reflorestamentos que vêm sendo praticados em larga escala no país, prevêm a utilização desta matéria-prima em futuras realizaçôes industriais, como essência papeleira de reflorestamento.

\section{SUMMARY}

Samples from of the Hondurensis variety of the Caribeae Pine were studied from the pulp and paper Stand point. In this paper we present the Geographical distribution of tropical pine forestry, the utilization of this species as raw material for the pulp paper industry in some developing countries, as well as the results of the research in aspects of its utilization. Discription of collecting sites, characteristics of the experimental plantations, classification and micrometry of the Fibers, culities of the chemical, semichemical, chemimechamical of the pulps, bleaching, semibleaching and anbleaching pulps and the results of some processes are presented. Conclusions were not similar to that of Pines of the Northern Hamisphere, yet the quality of the pulp this wood suggests that this pine is an interesting species for tropical Paper nıarker's reforesting programs.

\section{BIbLIOGRAFIA CitAdA}

CHANG, WONG WING ET ALII

1973 - An exploratory of the suitability of Pinus Caribeae for the production of dissolving pulps. Bul. - Tropical Products Institute, (L28) : 1-13.

CLARK, V. D' A

1962 - Effects of Fiber coarsenss and lenth. I - Bulk, Burst, Fold and Tensive Tests TAPPI, (8) : 45 .

DuboIs, R.

1966 - Une graude usine de pâte a papier on Afrique Bois et forêts des tropiques, Nogent-sur-Marne, (107) : 49-59.

Dubors, V. L. C.

1971 - Silvicultural Researel in the Amazon-FO: SF/Bra 4 - Technical Report 3 - United Nations Development Programme. Rome. Food and Agriculture Organization of the United Nations.

Holdrige, LesLie R.

1956 - Middle America, in a World geography of foust ressources. New York - The Ronald press Company, $183: 200$.

1970 - Organization de las Naciones Unidas para a agricultura y la alimentacion Boletim forestal y de industrias forestales para a America Latina. Abril/junio, 1970 - Lasilla 10095 - Santiago do Chile. 
PETROFF, G. ET ALII

1968 - Caractérisques papetiéres de quelques essences tropicales de reboisement. Nogent-sur-Marne - Centre Technique Forestier Tropical, $3: 174,156,174$.

PALMER, E. R. ET ALII

1969 - The pulping characteristics of Pinus Caribeae from Trinidad. Bul. Tropical Products Institute, (15) : 1-49.

1970 - The pulping of Pinus Caribeae Var. Bahamensis from great abaco Island, Bahamas. Bul. Tropical Products Institute, (L 23) : 1-32.

1971 - The pulping characteristics of Pinus Caribeae from Seaqaqa, Fiji. Bul.-Tropical Products Institute, (L 24) : 1-23. Pulping characteristics of nine - year old Pinus Caribeae from Sabah. Bul. Tropical Products Institute, $37 \mathrm{p}$.

1972 - The pulping characteristics of Pinus Caribeae from the in Growing areas in Fiji, 1971. Bul.Tropical Products Institute, (L 27) : 1-60.

1973 - Pulping characteristics of threes of Pinus Caribeae With diferent denrities grown in Jamaica. Bul. Tropical Pro. ducts Institute, ( $L$ 30) : 1-23.
1974 - Pulping qualities of plantation grown Pinus patula and Pinus elliotii from Malawi. Bul. Tropical Products Institute, (L 37) : 1-31.

SEWANDONO, R.

1956 - Southeast Aria in a World geography of forest ressources, 491:517 - New York - The Ronald press Company.

TIssot, M.

1968 - Caractéristique papetière de quelques pins introduits en Afrique et a Madagascar. Bois et forêts des tropiques, Nogent-sur-Marne, (118) : 41-57.

United Nations DeVelopment Programme

FAO No SIS - 14

1974 - The Technical and Economic Appraisal of au Export Marret pulp industry or Export Clip Industry. Rome. Report to the Government of Surinam - Food Agriculture Organization of the United Nations.

VILARS, V.

1975 - La pâte mécanique: Ceudrillon Papetière. Papier Carton \& Cellulose, (6) : 60-64. 